\title{
A Critical Update of the Assessment and Acute Management of Patients with Severe Burns
}

\author{
Thomas Charles Lang, ${ }^{1, *}$ Ruilong Zhao, ${ }^{2}$ Albert Kim, ${ }^{3}$ Aruna Wijewardena, \\ John Vandervord, ${ }^{4}$ Meilang Xue, ${ }^{2}$ and Christopher John Jackson ${ }^{2}$ \\ ${ }^{1}$ Department of Anesthesia, Prince of Wales and Sydney Children's Hospitals, Randwick, Australia. \\ ${ }^{2}$ Sutton Laboratories, The Kolling Institute, St. Leonards, Australia. \\ Departments of ${ }^{3}$ Critical Care Medicine and ${ }^{4}$ Burns, Reconstructive and Plastic Surgery, Royal North Shore Hospital, \\ St. Leonards, Australia.
}

Significance: Burns are debilitating, life threatening, and difficult to assess and manage. Recent advances in assessment and management have occurred since a comprehensive review of the care of patients with severe burns was last published, which may influence research and clinical practice.

Recent Advances: Recent advances have occurred in the understanding of burn pathophysiology, which has led to the identification of potential biomarkers of burn severity, such as protein C. There is new evidence about the potential superiority of natural colloids over crystalloids during fluid resuscitation, and new evidence about components of initial and perioperative management, including an improved understanding of pain following burns.

Critical Issues: The limitations of the clinical examination highlight the need for imaging and biomarkers to assist in estimations of burn severity. Fluid resuscitation reduces mortality, although there is conjecture over the ideal method. The subsequent perioperative period is associated with significant morbidity and the evidence for preventing and treating pain, infection, and fluid overload while maximizing wound healing potential is described.

Future Directions: Promising developments are ongoing in imaging technology, histopathology, biomarkers, and wound healing adjuncts such as hyperbaric oxygen therapy, topical negative pressure therapy, stem cell treatments, and skin substitutes. The greatest benefit from further research on management of patients with burns would most likely be derived from the elucidation of optimal fluid resuscitation protocols, pain management protocols, and surgical techniques from randomized controlled trials.

Keywords: burns, acute care, inflammation, biomarker, healing, perioperative care

\section{SCOPE AND SIGNIFICANCE}

BURNS ARE COMMON, with an annual global incidence of 11 million people, which is higher than the combined total incidence of tuberculosis and human immunodeficiency virus (HIV). ${ }^{1}$ Hospital admissions are lengthy ${ }^{2}$ and costly ${ }^{3}$ and inpatient mortality in developed countries is approximately $4-5 \%, 2,4$ which is similar to mortality incidence of acute myocardial infarction ${ }^{5}$ and pulmonary embolus. ${ }^{6}$ This article focuses on recent advances and influential findings relating to resuscitation and perioperative management of patients

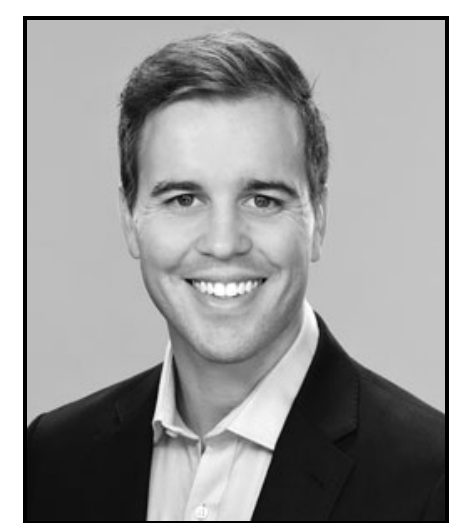

Thomas Charles Lang, MBBS, BAppSc (Phty)

Submitted for publication February 4, 2019. Accepted in revised form April 18, 2019.

*Correspondence: Department of Anesthesia

Prince of Wales and Sydney Children's Hospitals, Barker St., Randwick, NSW 2031, Australia

(e-mail: thomas.lang@sydney.edu.au). 
with severe burns. It provides clinicians with an up-to-date comprehensive summary of evidence to help guide future research and clinical practice.

\section{TRANSLATIONAL RELEVANCE}

This work is relevant to scientists involved in immunology, inflammation, circulation or coagulation, medical imaging, as well as researchers involved in the identification of biomarkers or the development of randomized controlled trials (RCTs).

\section{CLINICAL RELEVANCE}

The diagnostic value of current assessment methods and the safety and efficacy of current treatments are critically appraised in light of recent advances. This is directly relevant to clinicians caring for patients with severe burns. In particular, this includes surgeons caring for patients throughout admission, but also is directly relevant to emergency medicine physicians, intensive care physicians, anesthesiologists, pain specialists, internal medicine physicians, pathologists, nurses, and allied health staff.

\section{BACKGROUND}

Burns have been studied for centuries. ${ }^{7}$ In 1905 , a pioneer of burn management, Haldor Sneve, re- marked, "there is no more frightful accident than a severe burn of large area. The intense suffering of the patient, and, in case of recovery, the hideous deformity left, render these accidents peculiarly distressing." A severe burn is an acute wound caused by local thermal exposures that leads to lifethreatening systemic effects. ${ }^{9}$ The management of acute wounds resulting from radiation, friction, electrical currents, and caustic chemicals are dealt with elsewhere. The destruction of healthy skin (as shown in Figs. 1-3) is characterized by coagulation and denaturing of proteins. ${ }^{10} \mathrm{~A}$ severe burn wound differs from other acute wounds by the nature of its size, heterogeneity of depth, its dynamic nature, and systemic effects.

To illustrate the issue of size of the wound, a burn affecting $80 \%$ of the total body surface area (TBSA) means loss of $\sim 1.5 \mathrm{~m}^{2}$ of healthy epidermis and dermis. A given burn will be heterogenous with regard to the depth of the burn, and the depth of a burn can progress over time even after the initial insult has occurred. This process is called burn conversion. ${ }^{11}$ Human epidermis is $0.1-1 \mathrm{~mm}$ thick and the dermis is 1-4 mm thick, depending on the region involved. ${ }^{12}$ Loss of both dermis and epidermis leads to poor healing outcomes, and determines management. ${ }^{11}$ Therefore, there is interest in determining burn depth with great accuracy. ${ }^{12}$ Burns
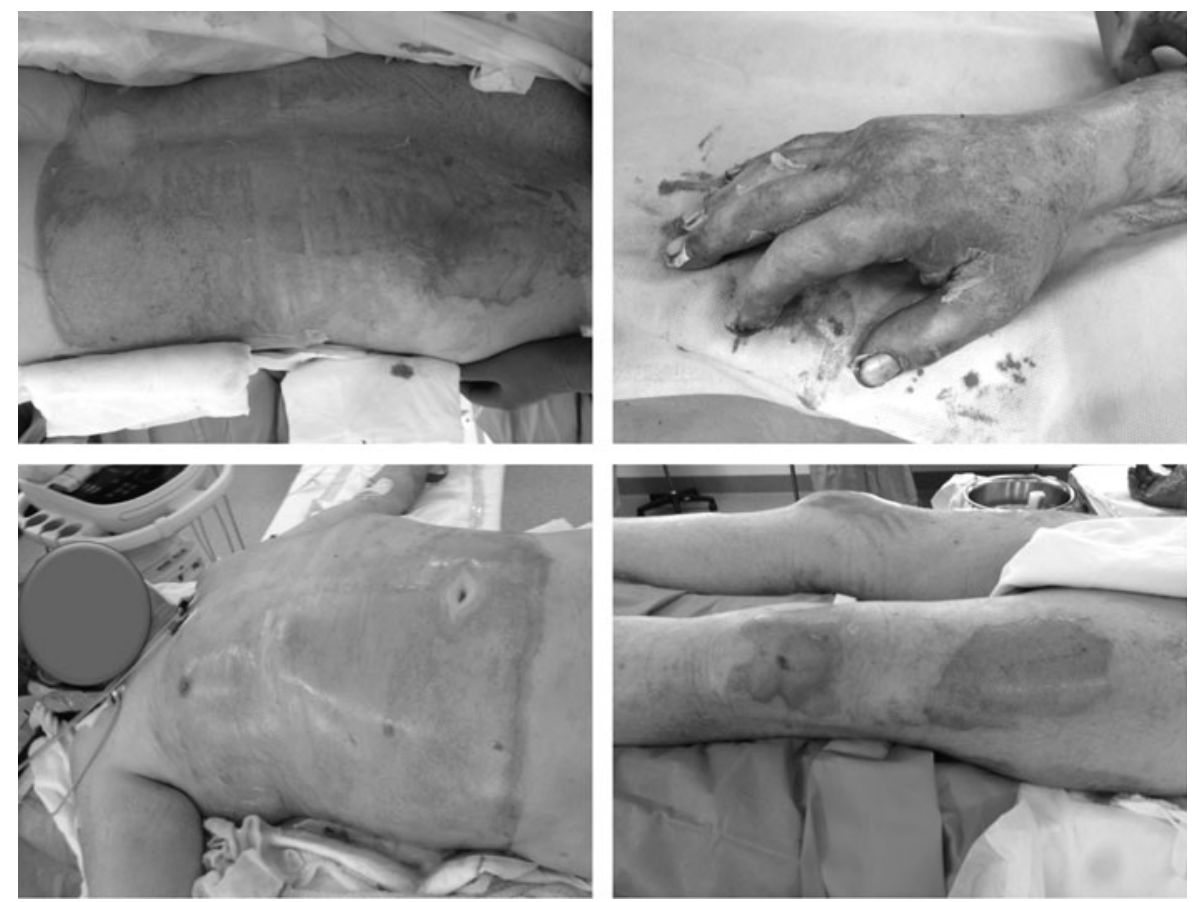

Figure 1. Severe burns. The patient is a 52-year-old male with $33 \%$ TBSA flame burns to the back, chest, abdomen, lower limbs, and hands, which were predominantly partial thickness. These photos were taken on admission to hospital. He received a mean daily intravenous fluid volume of $3.3 \mathrm{~L}$ over the first $72 \mathrm{~h}$, underwent three procedures for excision and grafting, and remained in hospital for 14 days with a length of stay in ICU of 6 days. ICU, intensive care unit; TBSA, total body surface area. 

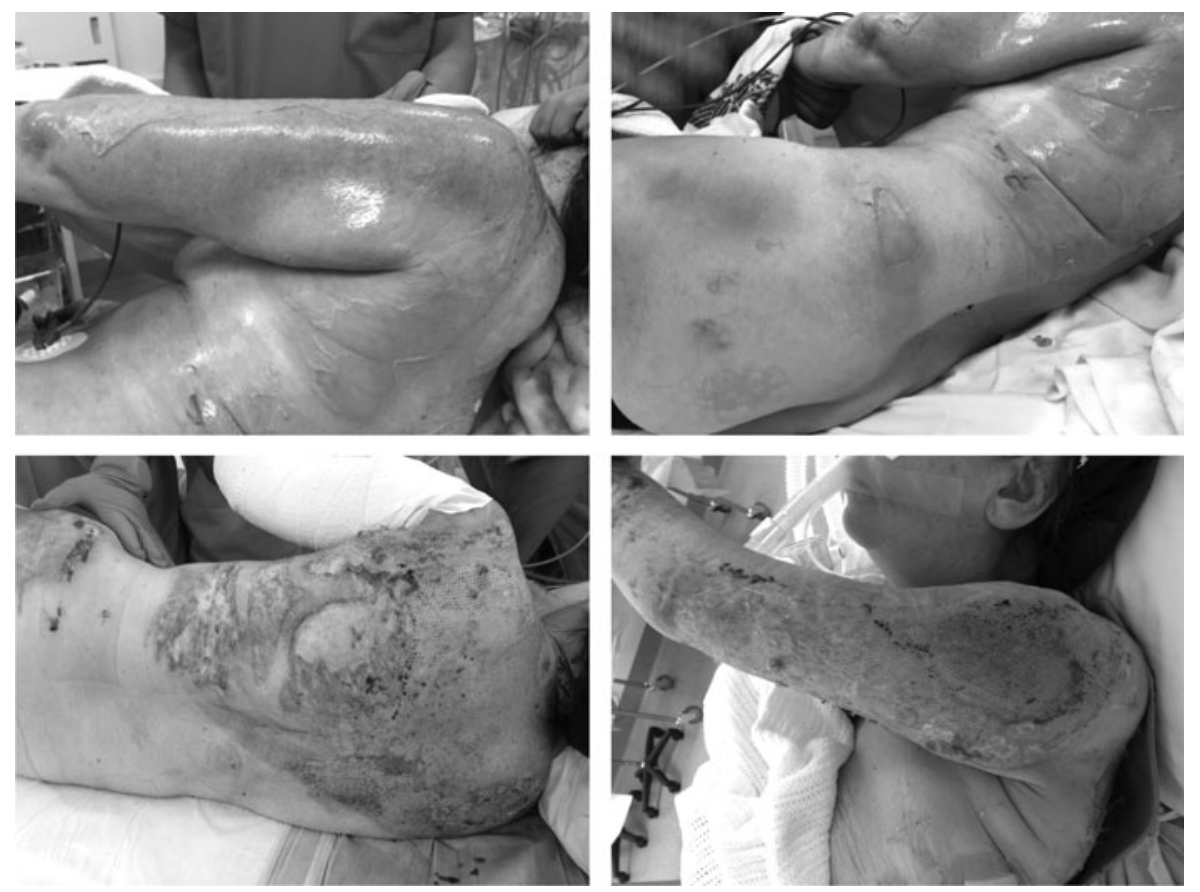

Figure 2. Severe burns. The patient is a 61 -year-old female with $12 \%$ TBSA flame burns to the back and upper arm, which were predominantly partial thickness. The upper two photos were taken on admission. The burns on the upper arm were excised and grafted the day after admission and again a week later. The lower two photos were taken 2 weeks after admission. She underwent three excision and grafting procedures, and remained in hospital for 21 days, two of which were spent in ICU.

can be conceptualized by concentric zones ${ }^{10}$ : coagulation is at the center, where skin tissue is destroyed, the zone of stasis surrounds this (where skin perfusion is reduced) and the zone of hyperemia surrounds this (where skin perfusion is increased). A burn may theoretically progress bidirectionally

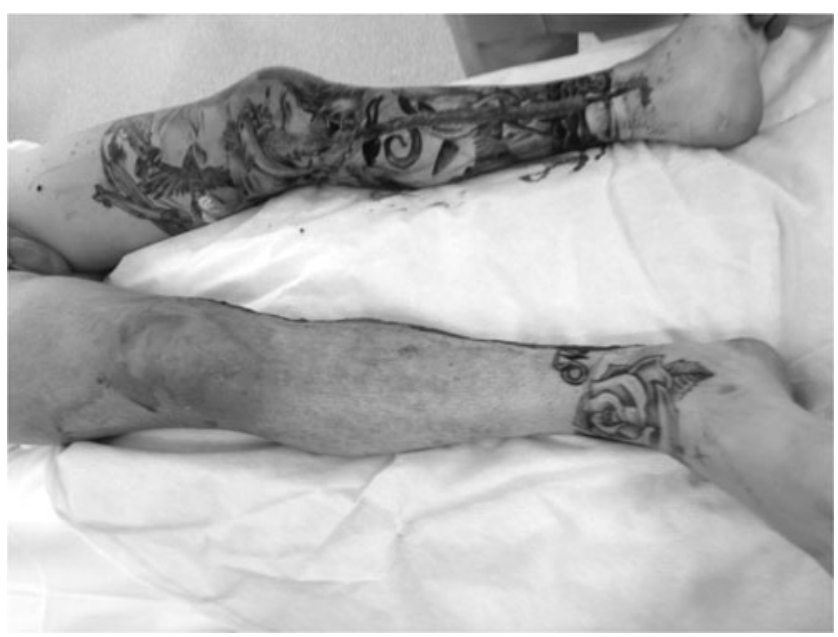

Figure 3. Severe burns. The patient is a 20 -year-old male with $18 \%$ TBSA superficial partial-thickness burns, primarily to the lower limbs. The circumferential burns were initially managed with fasciotomies and this photograph was taken on day 3 of admission. He underwent three excision and grafting procedures and remained in hospital for 10 days. through these zones. ${ }^{10}$ Finally, a burn causes widespread systemic effects. These effects will be discussed in detail in this review. Recent reviews on burns have focused on intensive care-related wound management, ${ }^{13}$ the metabolic response,${ }^{14}$ hypertrophic scarring, ${ }^{15}$ smoke inhalation, ${ }^{16}$ anesthetic and hemodynamic considerations, ${ }^{17}$ and developments in surgical techniques ${ }^{18}$; however, to our knowledge, this is the first review in recent years encompassing surgical, perioperative, anesthetic, and intensive care management.

\section{DISCUSSION: CRITICAL UPDATES Burn Pathophysiology}

\section{Excessive inflammation}

Patients with severe burns enter a state of "burn shock," which is characterized by poor tissue perfusion from profound capillary leakage, insidious coagulopathy, and widespread release of inflammatory mediators. ${ }^{19}$ Excessive inflammation is now well described following a burn injury, ${ }^{20}$ and this process is outlined in Fig. 4.

Important components of the immune response have been elucidated. Immune cells, such as antigen-presenting cells, and components of adaptive immunity, such as T-helper (Th)-1, Th-2, Th17 , and cytotoxic $\mathrm{T}$ cells are activated and release 


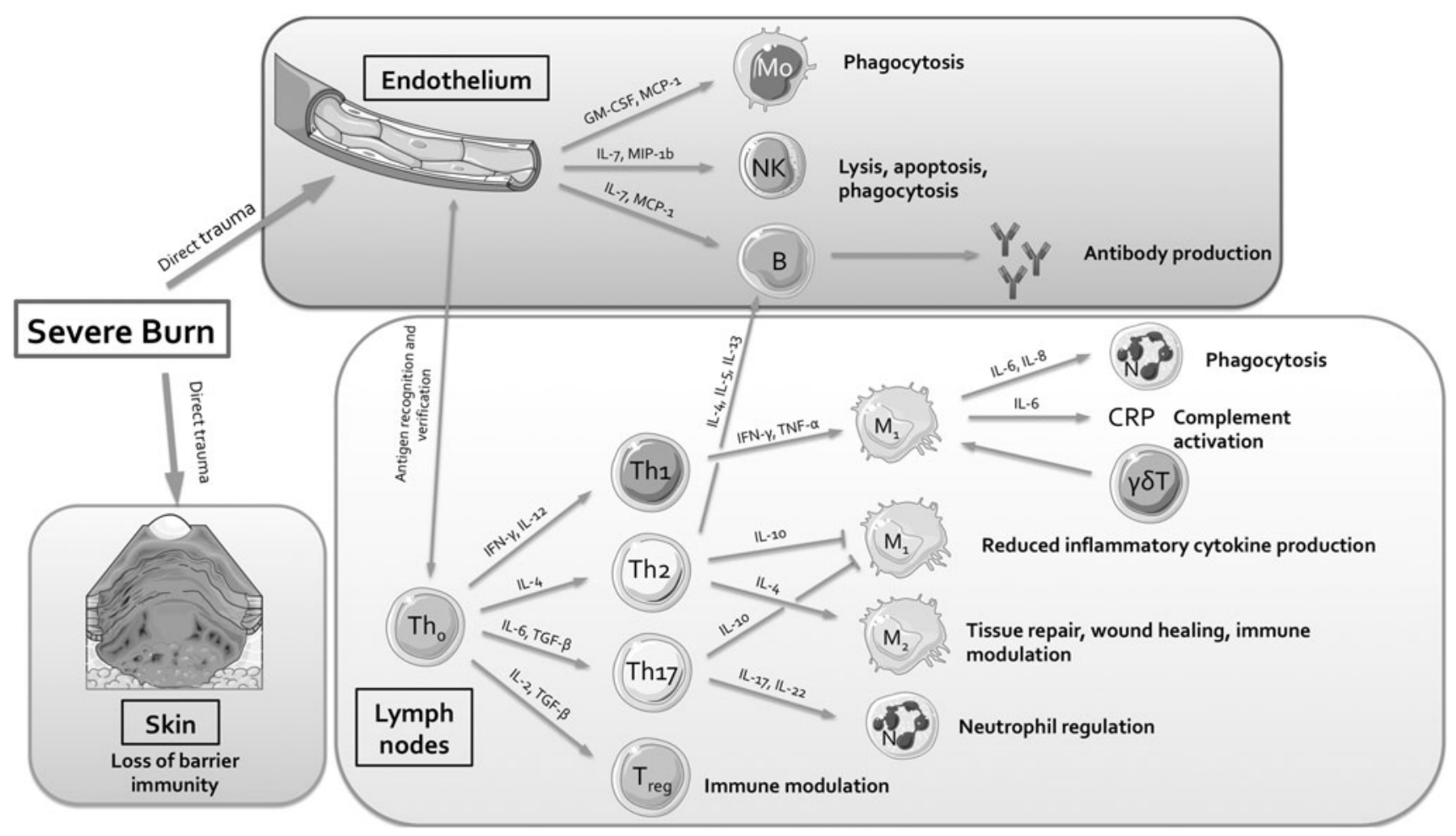

Figure 4. The immune response in severe burns. The immune response to a severe burn is widespread, poorly regulated, and prolonged. It is affected by massive fluid shifts due to increased vascular permeability as well as hemoconcentration and dysfunction of the coagulation system (not shown), which is closely linked to inflammatory dysfunction. Significant tissue injury causes the release of cytokines and chemokines from the endothelium, which activates proinflammatory effector cells to the site of injury. There is also upregulation and differentiation of T cells in the thymus, lymph nodes, and other locations, such as the skin. These T cells release a variety of chemokines and cytokines to draw effector cells to the site of injury, some of which are proinflammatory, and some of which are anti-inflammatory. All of the components in the diagram have been measured in animals or patients with severe burns or systemic inflammation, and excessive or suppressed activity levels of some of these components are associated with poor outcomes following a burn injury (please see Excessive inflammation for more details). $\gamma \delta$ T cells, gamma delta T cells; B, B cell; CRP, C-reactive protein; GM-CSF, granulocyte-macrophage colonystimulating factor; IFN- $\gamma$, interferon gamma; IL, interleukin; M, macrophage (M1 and M2 are subtypes of macrophage); MCP-1, monocyte chemoattractant protein-1; MIP-1 $\beta$, macrophage inflammatory protein-1 beta (also known as chemokine [C-C motif] ligand 4); Mo, monocyte; N, neutrophil; NK cell, natural killer cell; TGF $\beta$, transforming growth factor beta; Th, T-helper cell (Th0, Th1, Th2, and Th17 are T-helper cell subtypes); TNF- $\alpha$, tumor necrosis factor alpha; Treg, regulatory T cell. Figure was produced using Servier Medical Art.

cytokines to attract effector cells, such as granulocytes, to the burn. ${ }^{21-24}$ Immediately following major trauma and burns, the Th-1 response is attenuated, and the Th- 2 and Th-17 responses are dramatically enhanced ${ }^{25,26}$ and this leads initially to a state of immunosuppression. ${ }^{27}$ Granulocytes need to differentiate into neutrophils after suitable signaling to induce phagocytosis and to release web-like neutrophil extracellular traps (NETs). In a process called NETosis, NETs pick up cell debris with cell-free $\mathrm{DNA}^{28}$ and place cell-free DNA between cells to amplify inflammatory signals and localize chemokines to the site of injury. ${ }^{29}$ Highlighting the clinical relevance of NETosis, one recent study showed that neutrophil dysfunction, immature granulocyte count, and cell-free DNA levels strongly predict sepsis in burns. ${ }^{28}$ Along with necrosis and apoptosis, NETosis is an important process in the acute wound healing response. ${ }^{30}$
Gamma delta $\mathrm{T}$ cells $(\gamma \delta \mathrm{T}$ cells) also play an important role in the immune response to burn injury. ${ }^{31} \gamma \delta$ T cells modulate the inflammatory response, so their presence is likely to be beneficial following a burn, although it is unclear precisely how this process occurs. ${ }^{32}$ These cells are a unique innate immune system surveillance cell that exist within the skin and gut. ${ }^{33}$ They display increased toll-like receptor (TLR) reactivity following a burn. ${ }^{34}$ TLRs recognize pathogen-associated molecular patterns (PAMPs) from bacteria and damage-associated molecular patterns (DAMPs) from dead cells. They prime macrophages to produce proinflammatory cytokines, such as tumor necrosis factor alpha (TNF- $\alpha$ ) and interleukin (IL)-6. ${ }^{31}$

TNF- $\alpha$, which is secreted primarily by macrophages and Th-1 cells, is a proinflammatory cytokine central to the systemic inflammatory response syndrome and sepsis and is elevated in patients 
with burn injuries, ${ }^{22}$ with higher levels associated with the development of sepsis ${ }^{35}$ and lower levels associated with improved survival. ${ }^{36}$ IL- 6 is also a proinflammatory cytokine that modulates the acute phase of inflammation and is elevated in patients with burns particularly in the first week after a burn. ${ }^{37}$ C-reactive protein (CRP) is activated by IL- 6 and has been used clinically as a marker of inflammation but fails to predict both severe infection and sepsis in severe burns. ${ }^{38}$

IL-8 is a chemokine that attracts neutrophils and granulocytes to the burn site. It peaks shortly after a burn injury. ${ }^{39}$ Among burns patients who are mechanically ventilated, an elevated IL-8 level on days 0,3 , and 7 predicts death and ventilatorassociated pneumonia ${ }^{23}$ and among patients with large, severe burns requiring surgical intervention, IL-8 levels are significantly higher in nonsurvivors. ${ }^{40}$ Similarly, levels of granulocyte/macrophage colonystimulating factor (GM-CSF), and monocyte chemoattractant protein (MCP)-1 are higher among nonsurvivors of severe burns. ${ }^{40}$ Levels of other inflammatory cytokines that are elevated in the first week after a severe burn include: IL- $4,{ }^{40}$ IL-2, IL-5, IL-7, IL-12 and its active form p70, IL-13, IL-17, interferon- $\gamma$ (IFN- $\gamma)$, macrophage inflammatory protein $1 \beta,{ }^{37}$ and the inhibitory cytokine receptor IL-1 receptor antagonist. ${ }^{41}$

Enzymes, such as matrix metalloproteinase (MMP)-8 and MMP-9, are released from neutrophils in early inflammation in response to increased levels of GM-CSF, IL-8, and TNF- $\alpha .{ }^{42}$ MMPs break down the extracellular matrix and basement membrane in acute inflammation to contribute to vascular permeability ${ }^{43}$ and are inhibited by tissue inhibitor of metalloproteinases (TIMP)- $1 .{ }^{44}$ Circulating levels of TIMP-1 are maximal 2 days after a severe burn, ${ }^{45}$ are significantly higher in burns of $>20 \%$ TBSA compared with burns $<20 \%$ TBSA, and are significantly higher in patients who do not survive to 90 days after severe burn. ${ }^{46}$ Levels of plasma gelsolin, an intracellular actin-severing protein that stabilizes mitochondria to inhibit apoptosis, predict mortality at 28 days to a similar extent to the acute physiology and chronic health evaluation (APACHE) II score. ${ }^{47}$

\section{Hypermetabolism}

Patients with large burns have a significantly increased metabolic rate. This increase occurs in conjunction with the acute inflammatory response to injury, contributes to mortality, and persists for up to 3 years. ${ }^{48}$ Metabolic changes are seen primarily in the mitochondria in adipose tissue. After a severe burn, adipose tissue turns from white to beige and has increased amounts of mitochondria that are positive for uncoupling protein-1 (UCP-1). UCP-1 causes uncoupled mitochondrial respiration. This is characterized by inner mitochondrial membrane proton conductance that proceeds without the presence of adenosine triphosphate (ATP) synthase. Uncoupling is identified by mitochondrial heat production and alters the metabolic function of adipose tissue from the storage of energy to the expenditure of energy. ${ }^{49,50}$

Skeletal muscle also undergoes changes. Skeletal muscle oxygen consumption increases from 64 to $130 \mathrm{~mL} / \mathrm{min}$ after a burn of $50 \%$ TBSA. $^{51}$ This is thought to be explained by increased ATP production $^{52}$ and mitochondrial dysfunction characterized by the presence of UCP-2 (which acts similarly to UCP-1). ${ }^{53}$ Increases are also seen in ATP-consuming reactions required for protein synthesis, gluconeogenesis, and cycling of fatty acids. ${ }^{54}$

A burn injury also leads to central (hepatic) and peripheral (skeletal muscle) insulin resistance ${ }^{55}$ probably due to a postreceptor defect involving the glycogen synthesis pathways. ${ }^{56}$ Insulin resistance elevates circulating glucose levels. High glucose levels promote an aggressive hyperinflammatory phenotype of macrophages ${ }^{57}$ and natural killer cells ${ }^{58}$ and the mean amplitude of glycemic excursion over the first $72 \mathrm{~h}$ is an independent predictor of mortality. ${ }^{59}$

\section{Coagulopathy}

There is evidence of a link between inflammation and coagulation following burn injury. Using proteomic methods in patients with severe burns, investigators showed that a broad range of proteins involved in both inflammation and coagulation were significantly different between survivors and matched nonsurvivors (mortality in this study was defined as death from any cause and the mean time to mortality was $32 \pm 19$ days). For example, coagulation factor XIII, B polypeptide, and an antithrombin III variant (IPI00032179.2) were lower in nonsurvivors. This study also highlighted the relationship between nonsurvival and coagulation proteins, adhesion molecules (such as VCAM-1), inflammatory markers (such as TIMP-1, GM-CSF, IL-4, IL-8, and MCP-1), metabolic markers (such as retinol-binding protein 4 , sex hormone-binding globulin, CD-14, glycosylphosphatidylinositolspecific phospholipase D1, and proplatelet basic protein), and acute-phase reactants (such as IL-4, IL-8, and CCL2) following a severe burn. ${ }^{40}$

Low levels of the anticoagulant antithrombin III negatively correlate with increasing age and burn size, ${ }^{60}$ and reduced levels of the anticoagulants 
protein $\mathrm{C}(\mathrm{PC})$, protein $\mathrm{S}$, and antithrombin are associated with an increased risk of mortality. ${ }^{61}$ $\mathrm{PC}$ is a protease synthesized by the liver, ${ }^{62}$ vascular endothelial cells, and epidermal keratinocytes, ${ }^{63}$ which circulates in plasma as a zymogen of activated protein C (APC). ${ }^{62}$ In addition to its well-described anticoagulant function, which is to inhibit factor VIIIa and $\mathrm{Va},{ }^{62}$ APC exerts potent anti-inflammatory and cytoprotective functions. ${ }^{62}$ Following tissue injury, APC modulates the inflammatory response through intracellular signaling mechanisms, ${ }^{62,64,65}$ and in wounds it promotes controlled angiogenesis, ${ }^{66-69}$ and stimulates reepithelialization. ${ }^{70-72}$ This assists with the natural growth of well-vascularized granulation tissue from the base of the wound. It also facilitates cytoprotection through prevention of apoptosis and reduced inflammatory cell migration, which stabilizes the local cellular environment thus allowing and promoting the subsequent rapid growth of healthy new epithelium. ${ }^{69,73}$

PC levels are an independent predictor of the presence of a chronic wound in diabetic patients, to a greater extent than percentage of glycated circulating hemoglobin (HbA1c\%) or CRP levels. ${ }^{66} \mathrm{PC}$ levels are low in burns patients, ranging from $34 \%$ to $130 \%$ compared with the normal range of 70 $180 \% .{ }^{74}$ In sheep, PC levels decrease over the first $24 \mathrm{~h}$ after a burn ${ }^{75}$ and in an observational cohort study, we have recently shown that after a severe burn, PC levels are low and increase steadily over 6 days and then remain steady. This study showed that low PC levels are associated with large burns, deep burns, and poor outcomes, such as mortality, length of stay (LOS) in intensive care unit, number of surgeries, and a high volume of fluid resuscitation. ${ }^{76}$ This may be explained by excessive inflammation, as TNF- $\alpha$ suppresses $\mathrm{PC}$ activation, ${ }^{77}$ whereas IL-1 suppresses PC expression, ${ }^{78}$ and because both cytokines are increased immediately after a burn ${ }^{79}$ the PC system is shut off.

A detailed study of nine patients, including four nonsurvivors, who presented to hospital with severe burns with TBSA 25-95\%, was recently published. Investigators measured coagulation factors II, V, VII, VIII, IX, X, and XI; the anticoagulant proteins antithrombin III; PC; and tissue factor pathway inhibitor; the clot formation and fibrinolytic markers plasmin-antiplasmin complex; D-dimer and fibrin monomer; as well as the inflammatory cytokines IL-1 $\beta$, IL-6, IL-10, IL-12p.70, and TNF- $\alpha$ at regular intervals over the first $96 \mathrm{~h}$ of a hospital admission. The only markers with a significant difference between nonsurvivors and survivors on admission were PC activity levels
$(56 \% \pm 18 \%$ for nonsurvivors vs. $82 \% \pm 9 \%$ for survivors, $p=0.04$ ) and factor VIII activity levels $(518 \% \pm 182 \%$ for nonsurvivors vs. $305 \% \pm 148 \%$ for survivors, $p<0.05){ }^{79}$ The proposed functions of the PC system in patients with burns are outlined in Fig. 5.

\section{The Clinical Assessment of Patients with Severe Burns}

The initial resuscitation of a patient with burns allows rapid identification (and simultaneous treatment) of life-threatening injuries. Protocols vary in terms of resuscitation methodology, but a commonly used method is the Advanced Trauma Life Support algorithm. It is based on hierarchical and sequential management of the airway and cervical spine, ventilation, circulation and prevention of hemorrhage, assessment of neurological status, then identification of other injuries (including the burn) while maintaining normothermia. ${ }^{80}$ Following this, the patient undergoes a thorough head-totoe clinical assessment, the primary purpose of which is to rapidly determine burn severity by visually estimating burn depth and burn size. Burn size is estimated as a proportion of the TBSA affected by the burn and is important in early assessment as it guides the initial intravenous fluid resuscitation rate. Several methods assist this estimation. They include the rule of nines ${ }^{81}$ the rule of palms, ${ }^{81}$ the Lund and Browder chart, ${ }^{82}$ and other visual aids such as mobile apps. ${ }^{83}$

The means of categorizing burn depth varies between centers, but a generally accepted convention is to separate burns into one of three general categories of superficial, partial, or deep burns,

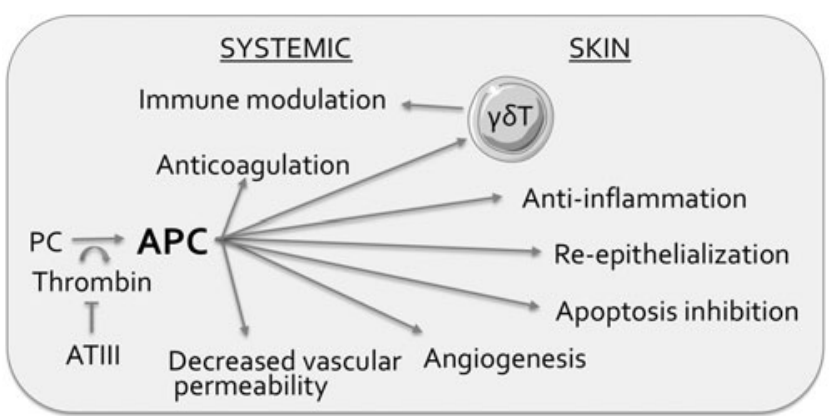

Figure 5. Proposed functions of the PC system in severe burns. PC is attached to the endothelial surface by endothelial PC receptor (not shown) and is cleaved by thrombin in response to tissue injury to produce APC. APC acts at the site of injury to manage the consequences of tissue damage and also has systemic effects on anticoagulation. APC is proposed to influence certain $T$ cell subtypes such as the gamma delta $T$ cell to influence modulation of the inflammatory response. APC, activated protein C; PC, protein C. Figure was produced using Servier Medical Art. 
with partial-thickness burns further subcategorized into superficial partial and deep partial thickness. ${ }^{84}$ Figures 1-3 show photographs of adults with predominantly superficial partial-thickness burns. Another purpose of the history and physical examination is to identify an inhalational injury. Patients who are suspected of having sustained an inhalational injury to the infraglottic airway or lung parenchyma may then undergo bronchoscopy for visual confirmation of damage to the respiratory epithelium.

Burns surgeons use clinical examination by visual estimation of burn size and depth as the primary method of evaluation in a patient with severe burns, and as the method that determines expected outcomes and therefore management. ${ }^{85}$ Although some surgeons consider clinical examination the gold-standard of patient assessment, ${ }^{86}$ there is evidence that visual estimations of depth are often inaccurate when compared with histologically determined depth, with expert surgeons unable to determine depth in up to $35 \%$ of burns. ${ }^{87-89}$ These methods have been validated but have limitations in reliability and as a result lead to inaccurate estimations, with recent research showing that nonhealth care-trained people are better at estimating burn size than expert surgeons. ${ }^{90}$ The primary implication of an unreliable estimation of burn size and depth is that the initial management (which is determined by the clinical examination) may be inappropriate.

Predicting inhalational injury with a purely clinical assessment is also difficult and error prone. Features, such as the presence of carbonaceous sputum, singed hairs, facial burns, and a burn in an enclosed space, were previously thought to provide evidence of an inhalational injury. However, each of these components of the history and physical examination are unreliable markers of inhalational injury when compared with findings on bronchoscopy. ${ }^{91}$ Clinicians have therefore labeled the history and physical examination as inappropriate for the diagnosis of inhalational injury. ${ }^{92}$ The implications of the history and physical examination as poor markers of inhalational injury include a limited ability to choose which patients require bronchoscopy and therefore detect true inhalational injury. This is important because inhalational injury confirmed by bronchoscopy and stratified by severity according to the Abbreviated Injury Score has been shown to predict inpatient mortality after a burn. ${ }^{93}$

Regression models derived from data based on the clinical examination are used to predict clinical outcomes following a burn. Examples of scores derived from these models include the Baux score ${ }^{94}$ the Zawacki score ${ }^{95}$ the Abbreviated Burn Severity Index, ${ }^{96}$ Roi's model, ${ }^{97}$ and the Unit Burn Standard Index. ${ }^{97}$ Among even the best regression models, however, none is properly validated, none provides odds ratios, and none is able to quantify the risk of a given outcome. ${ }^{98}$ For example, burn size and patient age are the best predictors of LOS, but even the best models cannot predict this outcome with a high degree of certainty, with the $\mathrm{R}^{2}$ statistic ranging from 0.15 to 0.75 for these models, meaning that between $15 \%$ and $75 \%$ of the variance in LOS can be predicted using the clinical examination. ${ }^{98}$

The visual inspection of the skin and upper airway after a burn has a limited capacity to detect the true nature of a burn injury. Tissue perfusion and necrosis cannot be identified by visual inspection. Therefore, adjuncts are required to accurately assess burn severity.

\section{Adjuncts to the clinical assessment of patients with burns}

Imaging. Laser Doppler imaging (LDI) provides information about regional tissue perfusion. When laser light is directed at perfused skin, circulating red blood cells scatter the light leading to a detectable Doppler shift, and a calculated estimation of blood flow follows. A systematic review and meta-analysis concluded that LDI has good diagnostic abilities (sensitivity 89\%, specificity 93\%) but that careful clinical assessment should be used alongside LDI for patients with full-thickness burns. A recent RCT showed LDI led to faster decision making about excision and grafting, and had a cost-saving benefit, ${ }^{99}$ and a recent study showed that LDI had superior specificity, sensitivity, positive predictive value, and negative predictive value than the clinical examination for estimating burn depth. ${ }^{100}$

There is some evidence to support the use of laser speckle imaging (LSI) in very small burns ${ }^{101}$ and although it has high specificity to detect deep dermal burns, it has limitations in sensitivity and accuracy. Spatial frequency domain imaging (SFDI) is noninferior to the physical examination in animal studies. ${ }^{102}$ Photoacoustic imaging was shown to be superior to LDI in detecting burn depth in animals, ${ }^{103}$ although a systematic review recently concluded that LDI is superior to other imaging modalities. ${ }^{104}$ Other imaging modalities to assess burn depth include near-infrared spectroscopy, ${ }^{105}$ ultrasound, ${ }^{106}$ skin quality probes,${ }^{107}$ nuclear magnetic resonance imaging ${ }^{108}$ capillary microscopy, orthogonal polarization spectral imaging, reflectance mode confocal microscopy, and polarization-sensitive 
optical coherence. ${ }^{109}$ These modalities require further testing before they are used routinely in the clinical setting.

The use of radiopaque contrast dyes and angiography remains in use but may be superseded by noninvasive imaging. The most commonly used dye is indocyanide green, which emits and absorbs energy within the near-infrared spectrum. The dye is injected intravenously before an imaging device is applied over the affected area of skin. The imaging device detects the presence of the dye within the affected area of skin using videoangiography. An image representing the amount of dye detected by the device can be mapped to create an image similar to that of the LDI to provide a representation of blood flow as a surrogate marker of burn depth. It is a highly accurate method of determining burn depth ${ }^{110,111}$ but it is associated with headache, pruritis, urticaria, and diaphoresis. It can only measure very small areas of blood flow (less than that of LDI) and it takes time and skill to set up the apparatus. ${ }^{109}$

Skin biopsies. In the setting of laboratory analysis and research, punch biopsies are considered the gold standard of measuring burn depth. A punch biopsy sample is typically stained with Hematoxylin and Eosin (H\&E). ${ }^{112}$ Other stains are also used. These include Masson's Trichrome stain (which is designed to detect the depth of burn and tissue necrosis) ${ }^{113}$ Verhoeff-Van Gieson's stain for elastic fibers, ${ }^{114}$ and an anti-vimentin antibody stain (which delineates a zone of necrosis). ${ }^{115} \mathrm{New}$ evidence suggests that the lactate dehydrogenase $(\mathrm{LDH})$ stain may be a superior alternative to the H\&E stain. ${ }^{112}$ However, reporting takes several days and fixation causes contraction of some portions of the skin sample and inaccurate estimations of depth. ${ }^{106}$ So while remaining useful for research, skin biopsies are not yet clinically useful. ${ }^{112}$

Biomarkers. Biomarkers have been defined as "any substance, structure, or process that can be measured in the body or its products and influence or predict the incidence of outcome or disease."116 In recent years, significant advances have been made in biomarkers that may be clinically useful in the care of patients with severe burns. Several candidates are listed in Table 1.

\section{The Acute Management of Patients with Severe Burns}

\section{Management of inhalational injury}

Once confirmed by bronchoscopy, several management options exist to reduce the likelihood of adverse outcomes associated with inhalational injury. There is evidence to support the early and ongoing use of chest physiotherapy, encouragement of coughing, and early ambulation. ${ }^{16,117}$ In intubated patients, continuous mechanical ventilation is associated with increased mortality and pneumonia incidence compared with ventilator modes with interrupted flow. These modes can incorporate different frequencies of flow interruption from the ventilator to the patient while maintaining positive airway pressure and are discussed in detail elsewhere. ${ }^{118,119}$

Pharmacological management options are better studied. There is evidence to support the use of the mucolytic agent nebulized N-acetylcysteine (NAC), the bronchodilator salbutamol and the anticoagulant nebulized heparin to reduce the duration of mechanical ventilation after inhalational injury. ${ }^{120}$ A dosing study showed that 10,000 IU of nebulized heparin per dose improved lung injury scores without influencing coagulation parameters. ${ }^{121}$ There is some evidence emerging to suggest that nebulized antithrombin is effective in reducing the incidence of pneumonia after inhalational injury. ${ }^{122}$

\section{Intravenous fluid resuscitation}

For over 100 years, it has been observed that the early provision of fluid after a burn is associated with reduced mortality. ${ }^{123}$ For 40 years the mineral composition and volume of intravascular and interstitial fluid compartments after a burn has been understood. Figure 6 outlines important concepts related to fluid compartments and intravenous fluid resuscitation. Hartmann's solution (a crystalloid solution) mimics the mineral composition of physiological extracellular fluid. A seminal publication by Baxter and Shires described the administration of Hartmann's solution to a series of patients with severe burns and a subsequent reduction in the typical mortality rate. ${ }^{124}$ These findings were then adapted to create a formula (the Parkland formula) to guide initial fluid resuscitation volume in the first $24 \mathrm{~h}$. It is typically defined as $4 \mathrm{~mL} / \mathrm{TBSA}$ burn \%/kg body weight. ${ }^{125,126}$ Most burn centers utilize the Parkland formula, ${ }^{125,126}$ but its use is associated with significant adverse events related to "fluid creep" such as abdominal compartment syndrome and pulmonary edema. ${ }^{127-129}$

Other formulae exist, such as the Modified Brooke formula and the Rule of Tens, and they also utilize body weight and burn size to determine the initial volume and rate of Hartmann's solution for resuscitation. ${ }^{130}$ The Modified Brooke formula suggests an initial intravenous fluid volume of $2 \mathrm{~mL} / \mathrm{kg} / \mathrm{TBSA}$ burn percent using Hartmann's 
Table 1. Potential biomarkers in severe burns

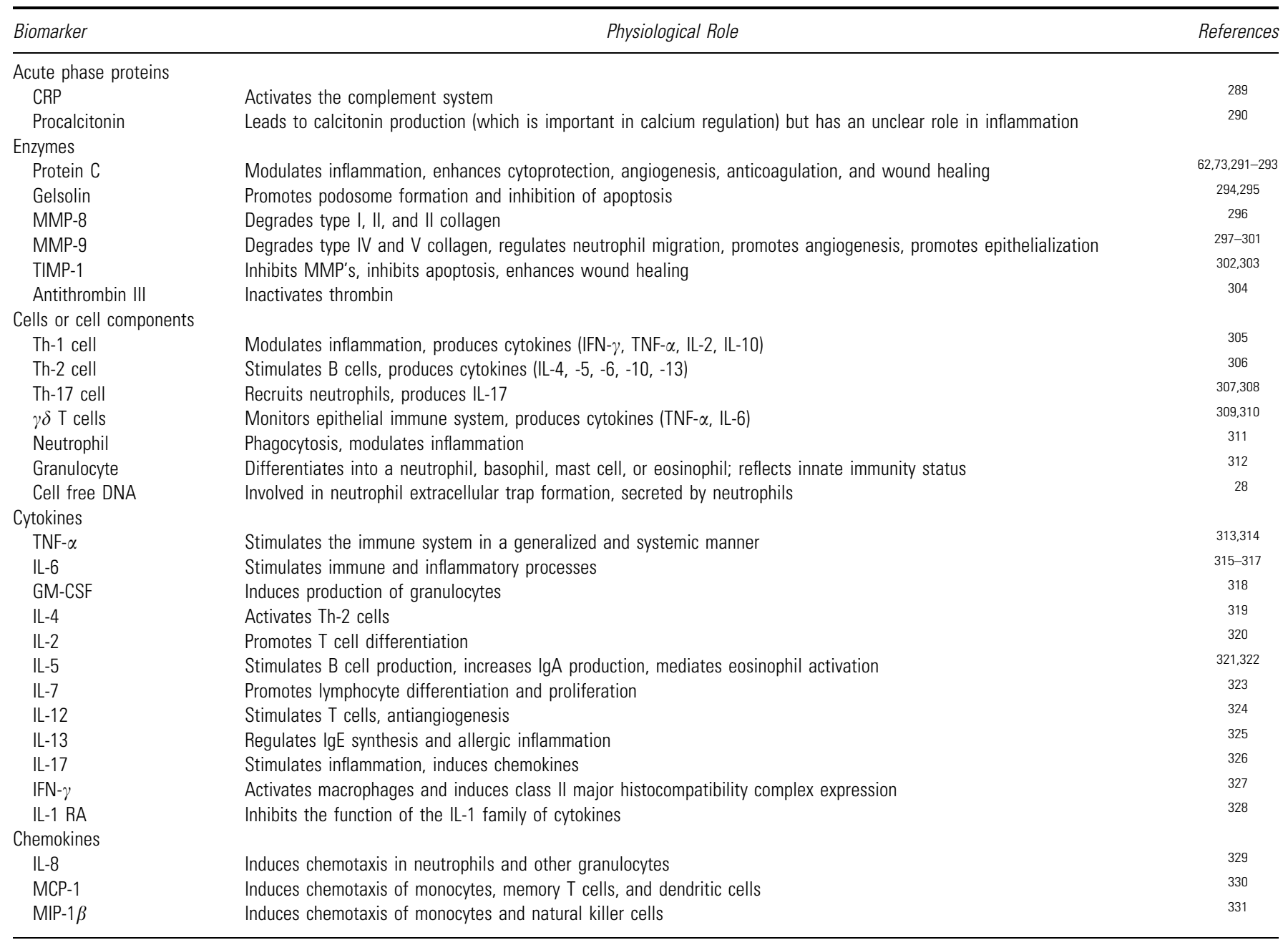

$\gamma \delta$ T cells, gamma delta T cells; CRP, C-reactive protein; GM-CSF, granulocyte-macrophage colony-stimulating factor; IFN- $\gamma$, interferon gamma; IL, interleukin; MCP-1, monocyte chemoattractant protein-1; MIP-1 $\beta$, macrophage inflammatory protein-1 beta (also known as chemokine [C-C motif] ligand 4); MMP, matrix metalloproteinase; Th, T-helper cell (Th0, Th1, Th2, and Th17 are T-helper cell subtypes); TIMP, tissue inhibitor of metalloproteinase; TNF- $\alpha$, tumor necrosis factor alpha.

solution over the first $24 \mathrm{~h}$, followed by a colloid solution at $0.3-0.5 \mathrm{~mL} / \mathrm{kg} / \mathrm{TBSA}$ burn percent over the subsequent $24 \mathrm{~h}$, with glucose in water added to maintain adequate urine output. ${ }^{131}$ The Rule of Tens is followed accordingly ${ }^{132}$ : burn size in TBSA perccent is estimated to the nearest $10 \%$. To determine the initial fluid rate in $\mathrm{mL} / \mathrm{h}$, this number is multiplied by 10 , for patients weighing $40-80 \mathrm{~kg}$.

Two U.S. Army publications suggest the use of non-Parkland fluid administration protocols following severe burn in a military casualty. One uses Hartmann's solution according to the Rule of Tens protocol in the first $24 \mathrm{~h}$ then $5 \%$ albumin in the second $24 \mathrm{~h},{ }^{133}$ and another uses the Modified Brooke formula to determine the initial resuscitation volume, and then suggests a switch to 5\% albumin after $12 \mathrm{~h}$ of Hartmann's solution administration for large burns and after $24 \mathrm{~h}$ for small burns. ${ }^{134}$ Protocols in hospitals vary similarly. ${ }^{125-129}$
One of the most striking and reproducible findings from recent studies of crystalloid fluid resuscitation in patients with burns, is a clear association between the volume of intravenous crystalloid administered and the incidence of adverse events related to interstitial fluid accumulation. There is a threshold volume of risk, somewhere between $250^{135,136}$ and $300 \mathrm{~mL}^{137}$ of intravenous crystalloid fluid administration per kg of body weight, particularly over the first $72 \mathrm{~h}^{137,138}$ that is associated with an increased risk of death, acute respiratory distress syndrome, pneumonia, intra-abdominal hypertension, and abdominal compartment syndrome. ${ }^{135-138}$

The alternative to a crystalloid solution is a colloid solution, and recent evidence shows that some colloids have a lower risk profile than that of crystalloids. Colloids contain macromolecules. In healthy patients, colloids remain within the intravascular 


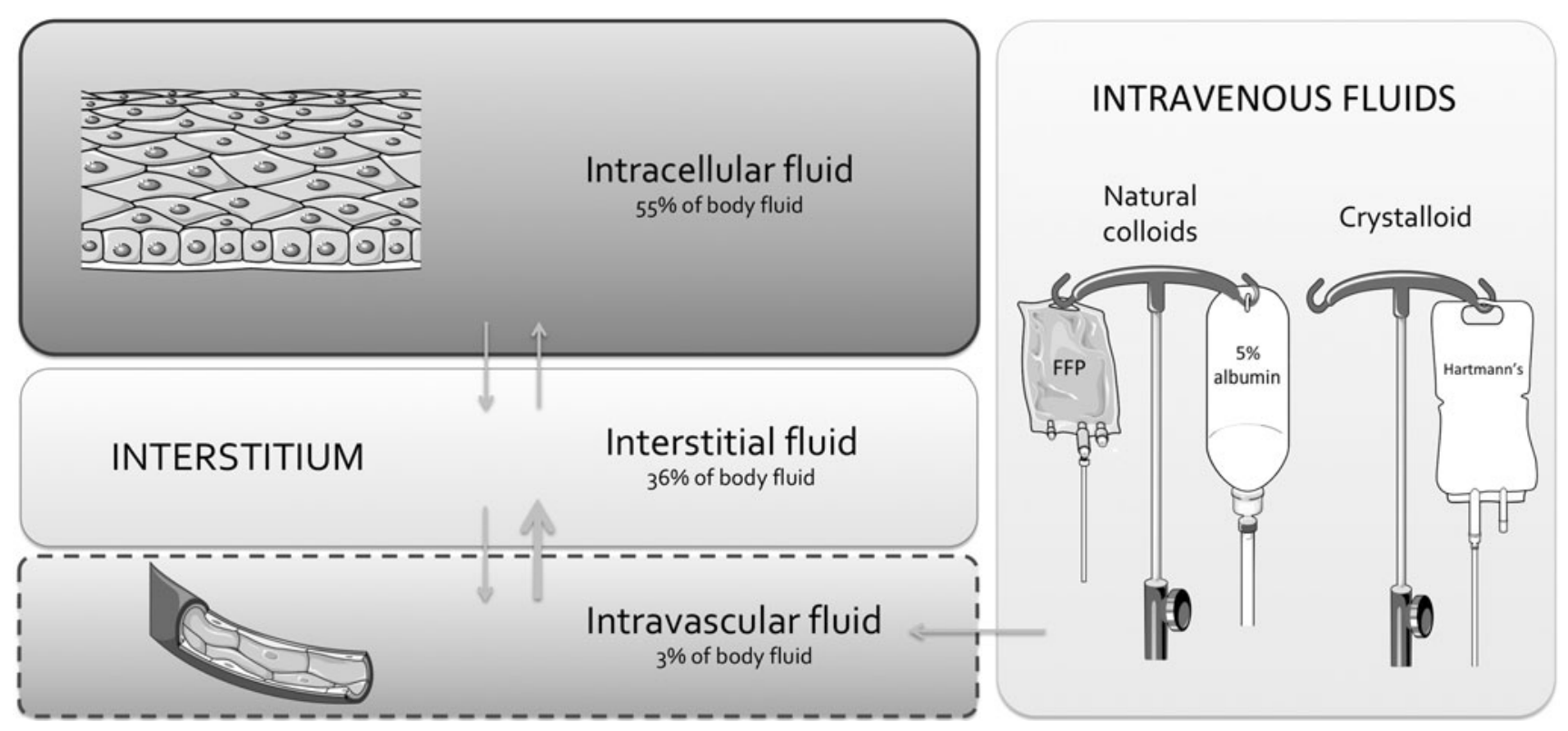

Figure 6. Fluid compartments and intravenous fluid resuscitation in severe burns. The human body is $60 \%$ water by weight and contains two virtual fluid compartments: the intracellular compartment and the extracellular compartment. The intracellular compartment holds $55 \%$ of body fluid and exists within all $10^{14}$ human cells, which make up tissues contained within muscle, skin, and solid organs. Fluid movement between the intracellular compartment and the extracellular compartment is tightly regulated by the semipermeable cell membrane and its ion channels and pumps. The extracellular compartment holds $45 \%$ of body fluid and is comprised of the interstitial compartment, and the intravascular compartment, as well as the water of dense connective tissue, bone, and transcellular fluid. Fluid resuscitation of a patient with burns directly affects the volume of the intravascuar, interstitial and the intracellular compartments. The interstitial compartment makes up $80 \%$ of the extracellular fluid and exists solely within the space between cells, while the intravascular compartment holds $7.5 \%$ of the extracellular fluid and exists solely within the vascular system. Fluid movement between the intravascular and interstitial space occurs through the capillary wall, which has increased permeability after a burn. The main goal of intravenous fluid resuscitation after a burn is to maintain tissue perfusion and this is thought to be achieved by maintaining a full intravascular compartment while avoiding overfilling of the interstitial compartment. Figure was produced using Servier Medical Art.

compartment to a greater degree and for longer than crystalloids, due to their greater oncotic pressure. ${ }^{139}$ The macromolecules in solution can be either natural or synthetic. The natural colloids available to use are albumin and fresh frozen plasma (FFP), while the synthetic macromolecules available are hydroxyethyl starch (HES) and gelatine. HES use is associated with acute kidney injury in critically unwell patients, and although there is no data on its efficacy or safety in patients with burns, it is scarcely used and generally avoided. ${ }^{140}$ Similarly, there is no data on the safety and efficacy of gelatine in patients with severe burns. ${ }^{19}$

Natural colloids, particularly 5\% albumin, have been better studied in patients with burns. In a randomized trial of 42 patients with severe burns, there was no difference in the incidence of multiorgan dysfunction syndrome (MODS) at any time point from days 0 to 14 postburn when comparing the use of Hartmann's solution to the use of Hartmann's solution plus 5\% albumin. ${ }^{141}$ However, in a retrospective study of 202 patients with severe burns, the use of $5 \%$ albumin during resuscitation significantly decreased the risk of mortality. ${ }^{142}$ Furthermore, a retrospective study of 159 patients with severe burns showed that, among patients who required high resuscitation volumes $(>6 \mathrm{~mL} /$ $\mathrm{kg} / \mathrm{h}$ at $12 \mathrm{~h}$ after the burn), the use of $5 \%$ albumin was associated with lower mortality, less mechanical ventilation days, lower incidence of ventilatorassociated pneumonia and open laparotomy for abdominal compartment syndrome, and better arterial partial pressure of $\mathrm{O}_{2}$ :fractional inspired $\mathrm{O}_{2}$ ratios at $24 \mathrm{~h}$ when compared with the use of Hartmann's. ${ }^{143}$

FFP is used in several resuscitation protocols. One trial compared FFP (administered according to the Slater formula) to Hartmann's solution (administered according to the Parkland formula). Patients who received FFP maintained an ideal urine output with significantly less fluid than patients who received Hartmann's $(140 \mathrm{~mL} / \mathrm{kg} /$ day vs. $260 \mathrm{~mL} / \mathrm{kg} /$ day, $p=0.005)$. Significant improvement was seen in patients who received FFP: patients had less weight gain, lower peak intra-abdominal pressures, lower peak inspiratory pressures, and faster and greater base deficit clearance. ${ }^{144}$ Another study compared FFP resuscitation to resuscitation with hypertonic saline and Hartmann's solution and found that the FFP group required less fluid in the first $24 \mathrm{~h}$ and still maintained the desired urine 
output yet gained less weight at both 24 and $48 \mathrm{~h}$ when compared with the other groups. ${ }^{145}$ Another study analyzed FFP-based resuscitation in patients with severe burns and showed decreased overall crystalloid fluid requirements when using FFP. ${ }^{146}$ Although there are rare reports of lung injury following FFP transfusion, ${ }^{147}$ and FFP is typically more expensive than crystalloids and albumin, ${ }^{148} \mathrm{a}$ retrospective review of 5 years' experience with FFP-based resuscitation described FFP as safe and effective for fluid resuscitation. ${ }^{149}$ Overall, these comparison studies suggest a trend toward a lower risk profile with initial natural colloid use compared with crystalloid use. There is however a lack of data from RCTs of fluid administration in patients with burns. RCTs would be invaluable to help determine best practice in fluid resuscitation following severe burns. ${ }^{19}$

Targeted fluid resuscitation. Adequate tissue perfusion is the goal of fluid resuscitation. It can be estimated by measuring cardiac output and blood oxygenation. These measurements can be used as targets to aim for during resuscitation. Patients with severe burns have had improved outcomes since the implementation of physiological targets during fluid resuscitation, ${ }^{150}$ but there does not seem to be a clearly superior method of measurement.

Blood oxygenation is measured directly and easily, whereas cardiac output measurement is more complex and indirect. The best and most reliable methods to measure cardiac output are transpulmonary thermodilution (TTD), intrathoracic blood volume index (ITBVI), and lithium dilution cardiac output (LiDCO). ${ }^{151-154}$ Pulmonary arterial catheter (PAC) measurements do not provide superior estimates of cardiac output to these less-invasive methods, ${ }^{151,152}$ therefore, PAC is not commonly used. Conversely, TTD, ITBVI, and LiDCO each require a peripheral arterial catheter. TTD and ITBVI involve analysis of a thermodilution curve recorded at the tip of an arterial line after the injection of a cold bolus in the circulation ${ }^{155,156}$ and LiDCO involves analysis of the arterial pressure waveform. ${ }^{154}$

Urine output (generally targeted at $0.5-1 \mathrm{~mL} /$ $\mathrm{kg} / \mathrm{h})^{157}$ has been used for decades to monitor the response to fluid resuscitation and is a good marker of organ perfusion. It is also not inferior to invasive hemodynamic monitoring methods with respect to patient outcomes, despite its inability to estimate cardiac output. TTD-guided resuscitation is associated with improved survival when compared with the use of hemodynamic parameters, ${ }^{158}$ but is not superior to urine output-guided resuscitation: there is no difference seen in mortality, hospital LOS, or central venous pressure. ${ }^{159}$ LiDCO-guided resuscitation is associated with lower crystalloid solution administration when compared with urine output-guided resuscitation, ${ }^{154}$ but there are no studies of clinical outcomes following LiDCOguided resuscitation. ITBVI-guided resuscitation is also not superior to urine output-guided resuscitation, with no difference seen in the incidence of MODS at 48 or $72 \mathrm{~h}$ postburn. ${ }^{160}$

Ascorbic acid. Studies of animal burn models show that intravenous ascorbic acid (vitamin C) infusion decreases capilliary permeability and fluid administration volumes ${ }^{161,162}$ and given the morbidity associated with overresuscitation, its use has recently become popular during fluid resuscitation. ${ }^{163}$ However, the only blinded RCT on ascorbic acid showed no differences in fluid intake at 24,48 , or $72 \mathrm{~h}$ when comparing patients who received ascorbic acid to patients who received the placebo, normal saline. ${ }^{164}$ There are also several safety concerns with ascorbic acid. First, it is a potent osmotic diuretic $^{163,165}$ and cases of profound hypovolemia have been reported with ascorbic acid infusion. ${ }^{166}$ Second, there are cases of nephrotoxicity following high-dose infusions, possibly related to calcium oxalate production. ${ }^{167}$ Third, ascorbic acid falsely elevates blood glucose levels. A false hyperglycemia may be erroneously treated and may lead to hypoglycemia. ${ }^{168}$

\section{Wound cooling and hypothermia}

The skin plays an important role in thermoregulation by regulating blood flow (which leads to modification of radiative and convective heat loss) and by regulating sweat production (which leads to modification of evaporative heat loss). ${ }^{169}$ Loss of dermal and epidermal tissue leads directly to impaired thermoregulation after a severe burn ${ }^{170}$ and this is highlighted by the positive association between burn size and the incidence of hypothermia. ${ }^{171,172}$ Most patients with severe burns arrive to hospital hypothermic $\left(<36.0^{\circ} \mathrm{C}\right) .{ }^{171}$ In nonburn trauma patients, hypothermia is considered part of the "lethal triad" along with coagulopathy and acidosis, ${ }^{173}$ and although no such "lethal triad" concept exists in burns management, hypothermia certainly appears to be harmful in burn patients. ${ }^{171}$ There is data to suggest that following a burn, hypothermic patients with severe burns have a shorter time to mortality ${ }^{171}$ and hypothermic patients with severe burns have a dramatically higher incidence of mortality $(60 \%$ vs. $3 \%)$ when hypothermia is defined as $<35^{\circ} \mathrm{C}$ and normothermia is defined as $\geq 36^{\circ} \mathrm{C}$. ${ }^{174}$ 
One animal study did show a prolongation of survival after inducing hypothermia in 36 rats with 40\% TBSA full-thickness burns, ${ }^{175}$ but another study of 40 rats with $40 \%$ TBSA full-thickness burns did not show an effect on survival after inducing hypothermia. ${ }^{176}$ Another study of 28 rats with $20 \%$ TBSA burns showed a mortality benefit and woundhealing benefit from directly cooling burn wounds with water ${ }^{177}$ and among dogs with burns, cool compresses applied directly to the burned area reduces edema formation, with the optimum temperature of the compress estimated to be $5-17^{\circ} \mathrm{C}$. Therefore, in animals, local cooling provides a wound healing benefit, however, targeted hypothermia in humans with severe burns does not seem to show a benefit and may indeed be harmful. Studies of local cooling in humans would be useful to determine any potential risk-benefit profile.

\section{Surgical management}

Burn excision. Following resuscitation, patients typically undergo early excision and grafting. Burn excision is the immediate removal of necrotic tissue in the area of the burn to a depth where viable bleeding tissue is identified. Excision is classically performed with a skin graft knife called a dermatome. Tangential excision is excision in repeated parallel slices with a dermatome, in contrast to the use of a scalpel to cut down to subcutaneous tissue. Early excision refers to the timing of tangential excision, which typically occurs within 2 days of injury. ${ }^{178}$ Several other methods of excision are in use. The most prominent alternatives to tangential excision are chemical debridement and hydrosurgery. Chemical debridement is performed with a bromelain-based debriding enzyme that is derived from the pineapple plant stem $\left(\right.$ Nexobrid $^{\circledR}$; MediWound Ltd.). It is prepared as a powder to be mixed with a gel for direct application to eschar. It removes necrotic tissue without damaging healthy tissue. It is associated with a reduced time to complete debridement, reduced need for surgery, reduced area of burns excised, and reduced need for autografting. ${ }^{179}$ Chemical debridement is far less painful than sharp debridement, so a general anesthetic is usually avoided. However, its use is associated with procedural pain therefore local or regional anesthesia and/or pre-emptive analgesia are required. Furthermore, bromelain is inhibited by topical products containing copper and silver so concurrent use of these products should be avoided. ${ }^{180}$

Hydrosurgery involves debridement with highvelocity, high-pressure saline directed at necrotic tissues. The best-studied hydrosurgery system is Versajet $^{\circledR}$ (Smith \& Nephew) and this has been superseded by a newer model (Versajet $\mathrm{II}^{\circledR}$; Smith $\&$ Nephew). Hydrosurgery has become popular for debridement and there is evidence to suggest that in most circumstances, it is as safe and efficacious as sharp debridement for devitalized, soft, necrotic tissue. ${ }^{181}$ Drawbacks include poor efficacy in removal of firm leathery tissue and a concern over potential contamination if infectious material is forced into deeper tissues, as well as concern over potential contamination of the operating room environment if infectious material is aerosolized. Hydrosurgery is initially far more costly than traditional sharp excision, although there is some evidence it is more cost effective in the long term. ${ }^{181}$

Grafting. Grafting is the harvesting of healthy skin from the patient (autografting) or a cadaver or living donor (allografting). Allografts are usually cadaveric. Animal grafts (xenografts) are typically porcine and often demonstrate acute rejection reactions and therefore are rarely used. ${ }^{182}$ The purpose of grafting is to achieve early closure of the burn wound, to provide a cover for the excised wound, and to supply it with epidermal cells to facilitate healing. Harvested skin is most commonly split thickness, although dermatomes can be adjusted to harvest full-thickness skin samples. The graft may be pressed and expanded to cover a large area. For most burns, adequate coverage is achieved with a meshing device that produces mesh-like grafts from the split-thickness skin graft (STSG). This is commonly referred to as the Tanner technique. These devices produce grafts with an expansion ratio between $1: 1$ and $9: 1$ of the initial harvested sample. Use of expansion ratios of $\geq 3: 1$ are typically used for burns $>50 \%$ TBSA. ${ }^{183}$

Early tangential excision and autografting has been the mainstay of surgical management of patients with severe burns. ${ }^{184}$ Early excision and grafting is associated with shorter hospital LOS and less blood loss than patients who undergo delayed excision and grafting. ${ }^{185}$ For burns of TBSA $<20 \%$, it is associated with shorter LOS and lower hospital costs than silver sulfadiazine (SSD) cream $^{186}$ and for burns of TBSA between $20 \%$ and $40 \%$, it is associated with a smaller number of wound debridements, less wound infections, and shorter hospital LOS when compared with no early excision and grafting. ${ }^{187}$ From animal studies, there does not appear to be a healing benefit from early excision within 2 days of injury compared with delayed excision within 7 days of injury, ${ }^{188}$ although scarring is increased with delayed excision 14 days after injury. ${ }^{189}$

Very large full-thickness burns ( $>70-80 \%$ TBSA) with limited donor sites may not be suited to tra- 
ditional STSG and may require the Meek technique to ensure adequate autograft coverage. ${ }^{190}$ The Meek technique involves cutting multiple squares of STSG $(42 \times 42 \mathrm{~mm}$ each) into 196 micrografts $(3 \times 3 \mathrm{~mm}$ each). Micrografts are placed on a pleated card that is unfolded to separate the micrografts. These grafts are then placed onto the excised area as individual "islands" that epithelialize and expand, and using this method, large areas of excised skin can be covered with STSG. The Meek technique appears to be a satisfactory method for autografting very large burns. ${ }^{191}$ A modification of the Meek technique also uses micrografts but the micrografts are covered by larger ready-to-use allografts. This is sometimes called the micrograft sandwich technique. After 2-3 weeks the allografts are carefully peeled away, leaving the micrografts to continue epithelialization. ${ }^{192}$ A modification to the micrograft sandwich technique has been described: after the removal of the allografts, cultured epithelial autografts (CEA) are placed at sites where the micrografts have not fully epithelialized. ${ }^{193}$ Retrospective data suggest similar clinical outcomes following the combined use of the micrograft sandwich technique and additional cultured epithelial autografts (M/CEA) when compared with traditional STSG, however, the M/CEA method was superior with regard to a smaller overall donor site and a lower cost of surgery. ${ }^{193}$

Autografting, particularly for facial burns, can lead to dissatisfaction about cosmetic results. ${ }^{194}$ Patients with very large burns may not be able to provide their own grafts, and therefore require allografts. Improved surgical techniques show promise to improve the issues of both cosmetic dissatisfaction and acute rejection that have been associated with allografting in the past. Vascularized composite allotransplantation (VCA) techniques have led to at least 30 successful hand and face transplants in patients with severe burns. Most patients remain on long-term immunosuppressive drugs after VCA. ${ }^{195}$ Although chronic immunosuppression is associated with the risk of infection, no VCA patients have had chronic graft rejection. ${ }^{194}$ Newer immunomodulation $^{196}$ and immunosuppressive therapies show positive preliminary results. ${ }^{182,197}$

Dehydrated human amnion/chorion membrane (dHACM) allografts (EpiFix, AmnioFix, EpiBurn; MiMedx Group, Inc.) have become popular in recent years. These allografts contain natural growth factors, cytokines, and chemokines. They are terminally sterilized and packaged as ready-to-use mesh or sheet dressings, or as a powder that can be mixed in saline for injection. Case reports show evidence that $\mathrm{dHACM}$ is a safe and effective graft option for partial- and full-thickness burns to the hands, face, and genitalia, although comparative trials would be useful. ${ }^{198}$

Skin substitutes. If early autografting is not feasible, for example if sufficient autograft is not available or not desirable due to the physiological condition of the patient, then temporary covers can be used (e.g., Integra ${ }^{\circledR}$ Dermal Regeneration Template; Integra Life Sciences Corporation, and Matriderm $^{\circledR}$; MedSkin Solutions Dr. Suwelack AG). Temporary covers are engineered to incorporate the growth of a neodermis and vascular network. They are widely used and allow temporary wound closure to facilitate healing. Integra is used commonly in the United States, and contains inert bovine tendon collagen and glycosaminoglycan scaffolding. The Integra Bilayer Matrix Wound Dressing has an additional removable semipermeable silicone layer. ${ }^{199}$ Matriderm is not available in the United States and consists of native collagen scaffolding and elastin and has shown to be useful in facial burns. ${ }^{200}$

Other covers are improving in quality and may become methods of permanent skin replacement, potentially avoiding temporary skin replacement and grafting altogether. ${ }^{201,202}$ Examples include allogeneic engineered skin substitutes (ESSs), autologous composite cultured skin (CCS) and threedimensional (3D) bioprinting.

ESSs are premade wound coverings that are made from allogeneic epidermal keratinocytes and dermal fibroblasts attached to collagen-glycosaminoglycan scaffolds. They offer the option of the immediate placement of healthy skin cells onto the wound bed without the need for a general anesthetic but carry a theoretical risk of rejection. Case reports describe excellent wound coverage and incorporation of ESSs by the host as functional skin, with cosmetic and functional results comparable to STSG and no cases of rejection. $^{203}$

CCS incorporates autologous cells and is undergoing testing in clinical trials of patients with burns. In this technique, skin biopsies are taken during initial excision to harvest fibroblasts and keratinocytes. Biodegradable polyurethane foam attached to an inert nonbiodegradable membrane is then immediately placed over the excised wound for temporary wound coverage and neodermis growth. The harvested cells are cultured in a bioreactor for 28 days to produce CCS. After 28 days, the membrane is removed and the CCS transplants are placed onto the neodermis. Preliminary results show complete healing with satisfactory cosmetic outcomes. ${ }^{202}$ A retrospective analysis 
showed no significant differences in hospitalization length for patients receiving allogeneic cells from ESS compared with patients with autologous cell techniques. ${ }^{204}$

Three-dimensional bioprinting is currently undergoing development for use in humans. One research group has successfully developed an in situ skin bioprinter that can print skin substrates directly to a wound. In one technique, fibroblasts are incorporated into a hydrogel of collagen and fibrinogen. This hydrogel is printed onto the wounds. Then a layer of keratinocytes is printed onto the hydrogel. These layers mimic the dermis and epidermis. Using this technique, full-thickness wounds in mice and pigs achieved complete reepithelialization in 8 weeks. $^{205}$ In another technique, amniotic fluid-derived stem cells and bone marrow-derived mesenchymal stem cells are suspended in a gel containing collagen, fibrin, and thrombin and are printed directly onto the wound. Then a second layer of the same gel is applied. ${ }^{205}$ Other groups have developed similar techniques mimicking the two-layer structure of skin, and have been able to print functional sweat glands in mice by using a composite hydrogel based on gelatin and sodium alginate. ${ }^{206}$

\section{Perioperative management}

Acute pain management. Pain is rated by patients, relatives, and staff as the most distressing part of critical illness. ${ }^{207}$ Effective acute pain management not only prevents unnecessary suffering acutely but also reduces the risk of the development of chronic and neuropathic pain ${ }^{208}$ primarily by damping the catecholamine-mediated stress response. ${ }^{209}$ After a burn, nociceptive $\mathrm{A} \delta$ and $\mathrm{C}$ neurons within the skin are activated. ${ }^{210,211}$ New evidence has shown that following a burn, the transient receptor potential channels transient receptor potential cation channel subfamily V member 1 (TRPV1) and transient receptor potential cation channel subfamily A member 1 (TRPA1; which are on the surface of nociceptive neurons) are activated by lipid agonists to cause nociception and allodynia. ${ }^{212}$ The stimulated $\mathrm{A} \delta$ and $\mathrm{C}$ neurons then synapse in the dorsal horn of the spinal cord to activate cortical pain pathways and this results in conscious perception of pain. ${ }^{211}$ This process of nociception is shown in Fig. 7.

Assessment of pain severity enables observation of quantifiable changes in pain in response to management. The most well-validated tools for pain
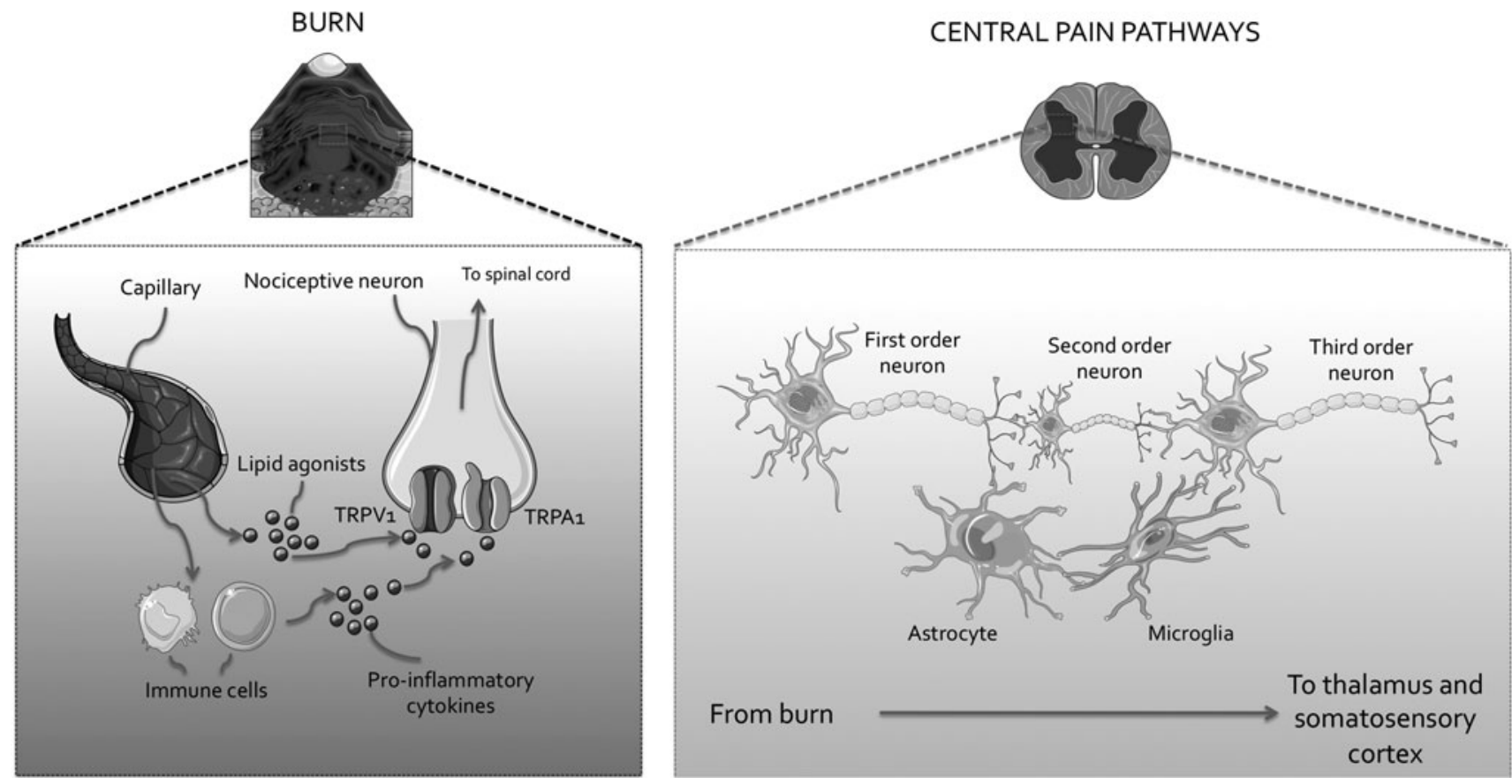

Figure 7. Nociception in severe burns. Local and systemic inflammation characterized by vascular release of lipid agonists and release of cytokines by immune cells cells is associated with activation of TRPV1 and TRPA1 in peripheral nociceptive neurons. These first-order neurons synapse with second-order neurons in the dorsal horn of the spinal cord, which synapse with ascending neurons within the spinothalamic tract. These neurons are sensitized by astrocytes and microglia. The spinothalamic neurons terminate in the thalamus then synapse to neurons which travel to the somatosensory cortex. The transmission of nociceptive stimuli to the cortex is modulated by descending inhibitory neurons (not shown). TRPA1, transient receptor potential cation channel subfamily A member 1; TRPV1, transient receptor potential cation channel subfamily V member 1. Figure was produced using Servier Medical Art. 
quantification in burns are the visual assessment scale (VAS) ${ }^{213}$ the burn-specific pain anxiety scale (BSPAS), ${ }^{214}$ and if the patient is on a ventilator, the critical care pain observation tool (CPOT) ${ }^{215}$ Acute pain severity does not correlate well with burn size or depth, ${ }^{216}$ therefore, pain severity should be considered separately from burn severity. Burn pain management should aim to provide background analgesia, and should allow for additional analgesia as required if pain worsens, for dressing changes or after surgical procedures. ${ }^{217}$

Opioids are now used far more in burns than previously, and this is independent of patient factors. ${ }^{218}$ They provide effective analgesia for severe pain. ${ }^{219}$ They should be used with caution as they are associated with side effects, such as sedation (which may be desirable), nausea, constipation, and dependence. $^{220}$ Another consideration with their use is that critical illness induces opioid tolerance through multiple proinflammatory mechanisms, including tightening of the P-glycoprotein-controlled blood-brain barrier, increased circulating levels of opioid-binding $\alpha$-1 glycoprotein, induction of opioidmetabolizing cytochrome P450, increased hyperalgesic opioid metabolite concentrations, increased intraneuronal protein kinase and $N$-methyl- ${ }^{-}$ aspartate (NMDA) concentrations, ${ }^{221}$ and persistent immune activation of the dorsal horn of the spinal cord by PAMPs and DAMPs released after tissue damage. Some key intracellular changes in opioid tolerance in burns are shown in Fig. 8. These changes lead to significant dose escalation to achieve adequate analgesia. ${ }^{222}$ Animal models show that burns directly reduce the antinociceptive effects of opiates ${ }^{223}$ and there are reports of increases in pain associated with opioid use in patients with burns, termed hyperalgesia. ${ }^{224}$ Some strategies to avoid opioid tolerance and hyperalgesia include limiting sedative infusions, considering neuraxial and non-neuraxial analgesia, rotating opioids, and utilizing multimodal analgesia ${ }^{222}$ with evidence to support adding clonidine and ketamine ${ }^{225}$ as well as methadone ${ }^{226}$ and dexmedetomidine. ${ }^{157}$ However, clonidine and dexmedetomidine can precipitate
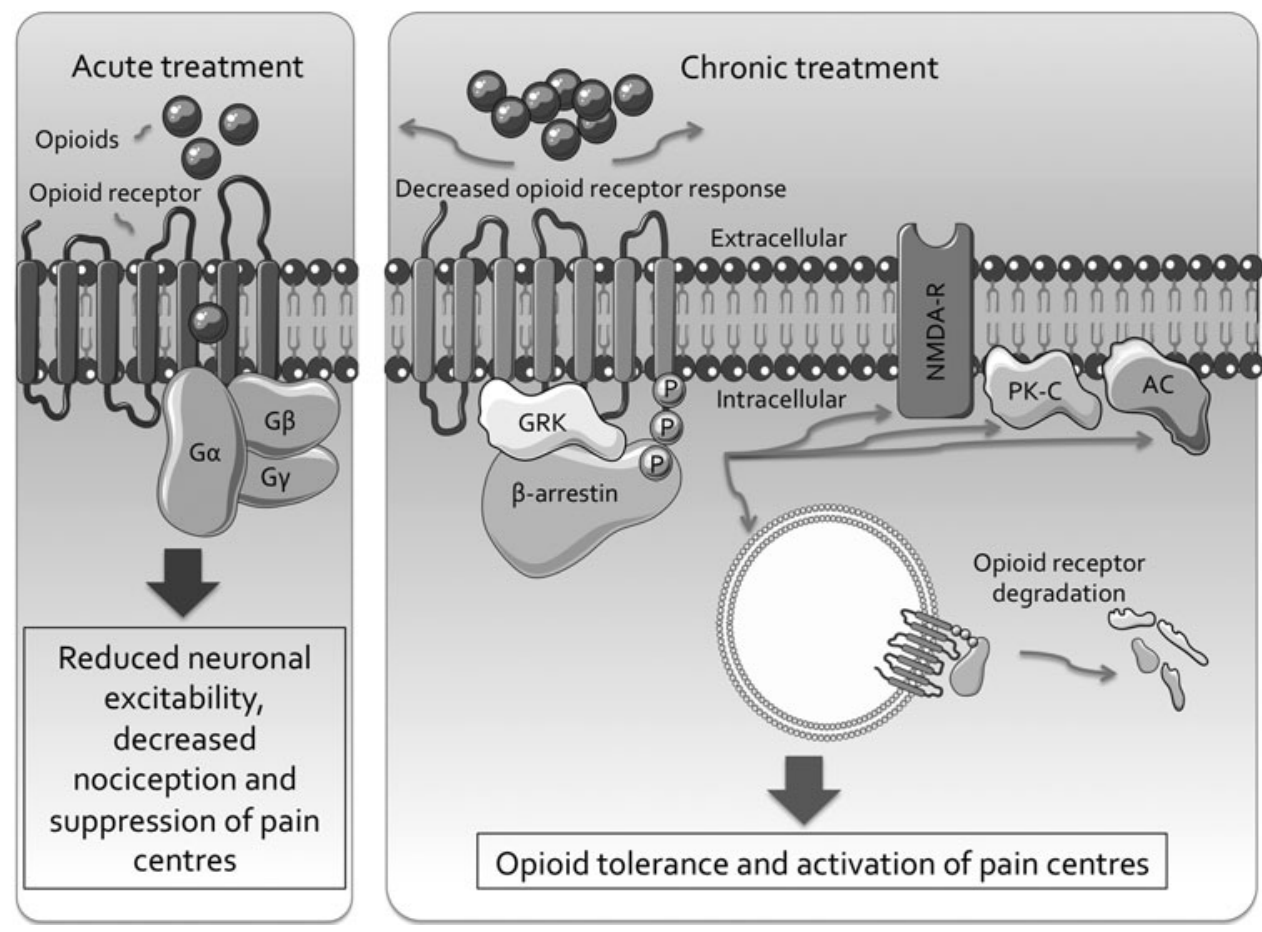

Figure 8. Opioid analgesia, tolerance, and hyperalgesia. During early treatment, opioids such as fentanyl and morphine bind to their opioid receptors in the cell wall of peripheral and central neurons. The opioid receptor is coupled with $\mathrm{G}$ proteins, which are composed of $\mathrm{G} \alpha \beta \gamma$ subunits. These subunits inhibit calcium channels and activate potassium channels leading to hyperpolarization of the neuronal membrane. The subunits also inhibit downstream AC enzymes, which decreases cyclic adenosine monophosphate levels. In the short term, these events reduce excitability and nociception and result in analgesic effects through decreased activation of the higher pain centers. However, after repeated exposure, particularly to morphine, opioid receptors become a substrate for G-protein-coupled receptor kinase (GRK), which leads to recruitment and binding of $\beta$-arrestin protein to the receptor. The opioid receptors are then less responsive to opioids and are degraded, leading to lower numbers of less-responsive opioid receptors, therefore increased doses are required to achieve the same effect on pain. Important intracellular events associated with this phenomenon in patients with burns include increased activity of AC (which increases cyclic adenosine monophosphate levels), increased phosphorylation by protein kinases (PK) and upregulation of $N$-methyl- ${ }^{-}$-aspartate (NMDA) receptors. AC, adenylate cyclase. Figure based on an illustration from Martyn et al. ${ }^{222}$ Figure produced using Servier Medical Art. 
hypotension in the hypovolemic patient, so should be avoided if the patient is hypovolemic. ${ }^{157}$

Intravenous opioid patient-controlled analgesia (PCA) shows greater efficacy than intermittent opioid injections with no difference in side effects. ${ }^{227}$ Fentanyl and morphine PCA protocols have recently been examined. The optimal fentanyl dose protocol involves a loading dose of $1 \mu \mathrm{g} / \mathrm{kg}$ followed by patientdemand boluses of $30 \mu \mathrm{g}$ with a lockout time of 5 min. ${ }^{228}$ An effective morphine regimen involves no loading dose, patient-demand doses of $1.5 \mathrm{mg}$ with a lockout time of $7 \mathrm{~min}$, and a $24-\mathrm{h}$ maximum dose of $180 \mathrm{mg}$, with up to three additional $3 \mathrm{mg}$ boluses every $4 \mathrm{~h}$ as required and other adjuncts such as midazolam and ketamine when required. ${ }^{229}$

For brief breakthrough analgesia during procedures, inhaled methoxyflurane is effective ${ }^{230}$ and it provides superior analgesia compared with a midazolam and ketamine PCA during dressing changes. ${ }^{230}$ Lidocaine infusion has been used for breakthrough pain but there is minimal evidence to support its use. ${ }^{231}$

Paracetamol (acetaminophen), nonsteroidal antiinflammatory drugs, and cyclo-oxygenase (COX)-2 inhibitors are effective to treat mild pain in patients with burns and exhibit a ceiling effect. ${ }^{232}$ However, they reduce opioid requirements and prevent opioid side effects such as nausea, vomiting, and sedation and thus should form part of the usual multimodal analgesia management. ${ }^{233}$ They act peripherally by inhibiting COX-2-mediated inflammation and centrally by modulating inflammation through activation of microglia. ${ }^{234}$ This is shown in Fig. 9. They are associated with gastrointestinal, and very rarely, renal and cardiovascular side effects ${ }^{235}$ so should be used with care.

Anxiety also plays a role in the unpleasant emotional response to acute nociception and there is evidence to support the use of any of the following: a midazolam infusion, a dexmedetomidine infusion, antipsychotics, or a propofol infusion (for less than $48 \mathrm{~h}$ only) to manage acute anxiety associated with burn pain. ${ }^{236}$ Of these agents, a midazolam infusion is the least preferred as it increases the risk of delirium $^{237}$ and dexmedetomidine the most preferred, as it has an additional analgesic effect and decreases opioid requirements. ${ }^{238}$

Studies of nonpharmacological pain management strategies have also shown efficacy in patients with burns. Hypnosis reduces pain anxiety and improves pain quality, ${ }^{239}$ virtual reality reduces pain scores and is most effective in patients with very severe pain, ${ }^{240}$ and transcutaneous electrical nerve stimulation appears to safely reduce acute pain. ${ }^{241}$

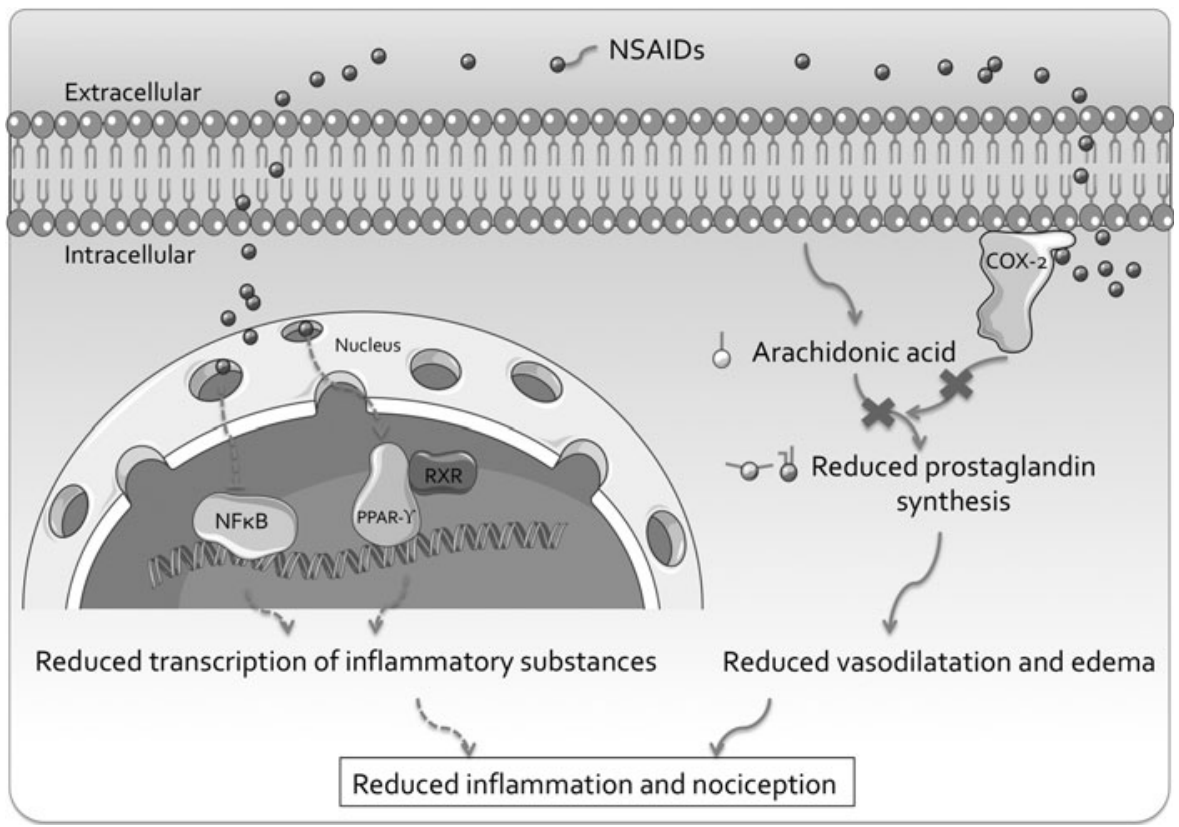

Figure 9. NSAID analgesia. NSAIDs bind to, and inhibit intracellular COX-2 and COX-1 (not shown). Their analgesic effect comes primarily from inhibition of COX-2. Inhibited COX-2 cannot convert arachidonic acid, which is derived from the cell membrane phospholipids, to prostaglandins such as prostacyclin. This leads to reduced vasodilatation and edema and reduced inflammation and activation of nociceptors, which is excessive in patients with severe burns. This is the primary mechanism of analgesia in NSAIDs, however, animal models have also shown non-COX-mediated analgesic mechanisms from NSAIDs within microglia. These include activation of PPAR- $\gamma$-RXR complex and inhibition of $N F \kappa B$, which together lead to reduced transcription of proinflammatory intermediates. COX, cyclo-oxygenase; $\mathrm{NF} \kappa \mathrm{B}$, nuclear factor kappa-light-chain-enhancer of activated $\mathrm{B}$ cells; NSAID, nonsteroidal anti-inflammatory drug; PPAR- $\gamma$, peroxisome proliferator-activated receptor-gamma; RXR, retinoid X receptor. Figure was produced using Servier Medical Art. 
Dressings and topical therapies. Nonocclusive dressings provide an initial temporary barrier to reduce bacterial contamination, improve skin healing, and reduce pain from movement of air over skin, or from direct contact to the burned or grafted area $^{242}$

Silver-containing dressings play an important role in the topical management of partial-thickness burns. ${ }^{243}$ Silver is a potent antimicrobial ${ }^{244}$ and can be used to treat (but not prevent) skin infections in burn wounds. Among silver-containing dressings, nanocrystalline silver, silver-impregnated foam, and silver-impregnated hydrofiber each appears to be superior to SSD in terms of infection control, LOS, time to healing, pain, and surgical intervention required. ${ }^{243}$ Nanocrystalline silver dressings (Acticoat ${ }^{\circledR}$ and Acticoat $7^{\circledR}$; Smith \& Nephew) appear to be superior to silver-impregnated foam (Mepilex ${ }^{\circledR} \mathrm{Ag}$; Mölnlyke Health Care AB) and silver-impregnated hydrofiber (Aquacel ${ }^{\circledR} \mathrm{Ag} \mathrm{Hy}-$ drofiber $^{\circledR}$; ConvaTec) in terms of LOS, healing time, infection control, and surgeries required. ${ }^{243}$ SSD is consistently associated with significantly slower healing times. ${ }^{245,246}$ Silver nylon dressings have been used in military casualties for decades, and a 10-year retrospective study of military casualties found no significant difference between patients treated with silver nylon dressings and several topical agents (mostly antimicrobial) immediately following a burn, with respect to the presence of a wound infection or the composite endpoint of wound infection, bacteremia, and/or mortality. These burns and trauma surgeons preferred silver nylon dressings due to ease of application and its light weight. ${ }^{247}$ Newer biosynthetic dressings (e.g., Biobrane ${ }^{\circledR}$; Smith \& Nephew) that contain nylon, collagen, and silicone (and no silver) show faster wound healing times, ease of application, and patient comfort, when compared with $\mathrm{SSD},{ }^{248}$ although more comparison studies between nanocrystalline silver dressings and biosynthetic dressings would be helpful.

Occlusive dressings are used postoperatively, particularly topical negative-pressure (TNP) therapy. TNP consists of a pump connected through tubing to an occlusive foam-based dressing covering the skin providing a constant negative pressure to the burn to draw moisture away from the burn while providing a temporary covering and promoting granulation tissue growth. One recent systematic review in burns did not find evidence to support its use and a systematic review in acute and chronic wounds concluded there was little evidence to support its use. ${ }^{249-251}$ However, a more recent literature review of a modified form of TNP found it to be a safe and effective temporary covering following early excision, particularly patients with large burns, with benefits of valuable quantification of wound exudate, reduction of opioid requirements, and lower risk of bacterial contamination. ${ }^{252}$

Regarding other topical therapies, some of which remain in use, there is clear evidence of a lack of effect for various types of honey ${ }^{253,254}$ and aloe vera $^{255,256}$ as well as platelet-rich plasma, ${ }^{257,258}$ curcurmin, ${ }^{259}$ fibroblast growth factor (FGF)-10, dermatan sulfate, ${ }^{260}$ ultraviolet $\mathrm{C}$ irradiation, ${ }^{261}$ and chitosan. ${ }^{262}$

Antibiotics. Outside of the operating theater, antibiotics and other antimicrobial agents such as silver should be used only to treat established infection. ${ }^{263}$ Established infection is important to diagnose, due to the risk of the development of sepsis. Sepsis has been recognized as a significant cause of death in patients with burns. ${ }^{264}$ Sepsis criteria have been clearly defined by the American Burn Association (ABA) although these criteria correlate poorly with blood culture-proven bacteremia. ${ }^{265}$ Newer markers of sepsis are being utilized. Procalcitonin is measured in clinical practice in patients with suspected infection. The site of production and physiological role in inflammation of procalcitonin are unclear. Although early studies assessing the prognostic utility of procalcitonin varied from supportive ${ }^{266}$ to dismissive, ${ }^{267}$ a recent meta-analysis and a subsequent study found that procalcitonin can clearly differentiate between a burned patient with sepsis and a burned patient without sepsis. ${ }^{268,269}$ Once established infection has been identified, it should be treated with an antimicrobial agent. Antimicrobial selection varies according to local pathogen resistance and prevalence, and the development of infection is influenced by the use of personal protective equipment, hand hygiene, and hospital culture. $^{270}$

There is evidence from a systematic review and meta-analysis of studies of 2,117 participants to support not routinely using antibiotics to prevent infection in severe burns. Compared with control treatments, prophylactic topical antibiotics increase the risk of burn wound infection (relative risk [RR] 1.37, 95\% confidence interval [CI] 1.021.82) and the use of silver sulfasalazine as a topical antibiotic increases infection rates by up to $80 \%$. Prophylactic topical antibiotics also increase the risk of sepsis (RR 4.31, 95\% CI 1.61-11.49), allcause mortality (RR 5.95, 95\% CI 1.1-32.33), and do not reduce the risk of bacteremia, pneumonia, 
urinary tract infection, adverse events, infectionrelated mortality, multiresistant Staphylococcus aureus (MRSA) colonization, or hospital LOS. Compared with control treatments, prophylactic systemic antibiotics increase the risk of any adverse outcome (RR 3.12, 95\% CI 1.22-7.97), MRSA colonization (RR 2.22, 95\% CI 1.21-4.07), hospital LOS (RR 7, 95\% CI 3.28-10.72), and do not reduce the risk of burn wound infection, sepsis, bacteremia, urinary tract infection, infection-related mortality, or all-cause mortality. ${ }^{271}$

The above data do not include the use of preoperative antibiotic use. A single preoperative dose of an appropriate antibiotic such as cefazolin (or other antibiotic as guided by local pathogen prevalence and resistance) $60 \mathrm{~min}$ before incision is important to prevent surgical site infection. ${ }^{272} \mathrm{~A}$ second intraoperative dose may be required if the operation exceeds $4 \mathrm{~h}$, and for prolonged major surgery, an infusion can maintain steady plasma antibiotic concentration. ${ }^{273} \mathrm{~A}$ single dose of preoperative antibiotic reduces the risk of surgical site infection particularly for autografting procedures. ${ }^{274}$ However, there is not yet clinical evidence to quantify the risks and benefits of preoperative antibiotics for newer minimally invasive debridement and grafting techniques.

Hyperbaric oxygen therapy. Hyperbaric oxygen therapy involves the use of $100 \%$ oxygen administered at pressures above 1 atmosphere. ${ }^{275}$ Its use to improve healing after burns is emerging. A Cochrane systematic review of RCTs from 2013 concluded that while further evaluation was required to support its use in acute surgical wounds, the trials with patients with burns showed promising results. When compared with usual treatment, the addition of hyperbaric oxygen improved complete graft survival (RR 3.5, 95\% CI 1.35-9.11) ${ }^{276}$ and subsequent work has shown a potentially beneficial role in controlling sepsis among patients with severe burns as measured by time to normalization of procalcitonin levels ( $136 \pm 23$ days vs. $84 \pm 7$ days, $p<0.001) .{ }^{277}$

Early nutrition, metabolic therapy, and exercise. Early consideration of nutrition is an important feature of modern burn management ${ }^{278}$ although the ideal type, timing, and amount of macronutrients to be administered are not known. One consensus article suggests initially delivering enteric carbohydrates at a rate of $5-7 \mathrm{mg} / \mathrm{kg}$ body weight/min, providing a total protein quantity of $1.5-2 \mathrm{~g} / \mathrm{kg}$ body weight/day and a total daily lipid quantity of $<20 \%$ of nonprotein stores.
However, optimal protocols are still being elucidated from animal models and high-quality evidence of improved outcomes in humans is yet to be established. ${ }^{279}$

Catabolic processes lead to the loss of muscle mass, strength, and therefore body function. Oxandrolone and somatropin have been used to prevent this. ${ }^{14}$ Oxandrolone is testosterone analog. In a systematic review and meta-analysis of RCTs, oxandrolone was shown to reduce body mass loss, nitrogen loss, and accelerate donor graft healing site time. ${ }^{280}$ Recombinant human growth hormone (somatropin) provides a clinically significant beneficial effect on healing time and LOS with a side effect of increased incidence of hyperglycemia. ${ }^{281}$

Hyperglycemia from insulin insensitivity is a well-established acute complication of severe burns and it should be avoided as it is associated with a risk of infection, catabolism, and excessive inflammation. ${ }^{282}$ Insulin controls hyperglycemia effectively in patients with burns. ${ }^{282}$ Its use is associated with hypoglycemia although this can be mitigated with target-guided protocols. ${ }^{283}$ Metformin, exenatide, and fenofibrate have a role in control of hyperglycemic control beyond the acute stage of management and their use is discussed elsewhere. $^{14}$

Catecholamines drive the hypermetabolic response and can be suppressed by $\beta$-blockade. The $\beta$-blocker propranolol is well studied in burns and a systematic review and meta-analysis of RCTs shows it to be safe and effective to reduce resting energy expenditure, trunk fat, increase peripheral lean mass, and reduce the incidence of insulin resistance. ${ }^{284}$ Exercise after hospital discharge has well-established benefits, and some evidence is emerging to support inpatient exercise. ${ }^{14}$

Upper gastrointestinal ulcer prophylaxis. Upper gastrointestinal ulcers occur in patients after severe burn and can lead to hemorrhage. ${ }^{285}$ They are also known as stress ulcers or Curling ulcers. Among patients with severe burns who undergo endoscopy, $38 \%$ of patients have either a gastric or duodenal ulcer, and the strongest predictors of ulcer presence are epigastric pain (OR 4.55, 95\% CI 1.74-11.9) and burn size of $>20 \%$ TBSA (OR $4.31,95 \%$ CI 1.34-13.85). There is no data from studies of patients with burns to support the use of stress ulcer prophylaxis, ${ }^{286}$ although guidelines based on findings from critically ill patients with stress ulcers support the use of stress ulcer prophylaxis for all patients with severe burns. ${ }^{287}$ Proton pump inhibitors are more efficacious than histamine receptor antagonists among 
critically ill patients for the prevention of stress ulcers. ${ }^{288}$

\section{SUMMARY}

Several advances have been made in the field of assessing and treating patients with severe burns. Examples of advances in assessment include quantification of the limitations of the clinical examination, improvements in noninvasive imaging technology, as well as elucidation of the pathophysiology of inflammation, metabolism, and coagulation, which has led to analysis of the potential role of biomarkers.

Regarding resuscitation, there have been advances in explication of the safety and efficacy of different fluid resuscitation protocols and there is evidence to support the use of targeted fluid resuscitation particularly with natural colloids, while ascorbic acid infusion during fluid resuscitation does not seem to have a clear benefit. For surgical management, early excision and grafting is commonly performed and advanced techniques such as vascularized composite allografting for total face and hand transplants are becoming more common. Regarding perioperative management, advances have been made in the use of pharmacological and nonpharmacological analgesia. Hyperbaric oxygen therapy, TNP wound therapy and skin substitutes (which includes 3D bioprinting) are emerging burn treatments. Biosynthetic dressings and nanocrystalline silver dressings appear to be superior to dressings or creams containing SSD. There is clear evidence of harm from the use of prophylactic antibiotics, and evidence of a lack of effect from honey, aloe vera, platelet-rich plasma, curcurmin, FGF-10, dermatan sulfate, ultraviolet $\mathrm{C}$ irradiation, and chitosan. Benefits are apparent with hyperglycemic control and anabolic medication. Pharmacological stress ulcer prophylaxis is recommended. Ideal nutritional supplementation regimens are still to be elucidated. The greatest benefit from further research would be derived from elucidation of optimal fluid resuscitation protocols and surgical techniques based on findings from randomized trials.

\section{ACKNOWLEDGMENTS AND FUNDING SOURCES}

No funding was sought or obtained.

\section{ETHICS APPROVAL}

Ethics approval was obtained for the period of March 18, 2015 to March 18, 2020 by the Human Research Ethics Committee (HREC) of the Northern Sydney Local Health District (NSLHD). HREC Reference: HREC/13/HAWKE/417, which included review of the National Ethics Application form NEAF AU/1/F4EB112. NSLHD Reference: 1312-409M.

\section{AUTHOR DISCLOSURE AND GHOSTWRITING}

C.J.J., J.V., and A.W. are shareholders in a company undertaking a trial of a 3K3A-APC in diabetic ulcers. For T.C.L., R.Z., and A.K., no competing financial interests exist. The content of this article was expressly written by the authors listed. No ghostwriters were used to write this article.

\section{ABOUT THE AUTHORS}

Thomas Charles Lang, MBBS, BAppSc(Phty), is an Anesthetics Registrar at Prince of Wales and 
Sydney Children's Hospitals with a special interest in critical illness and is undertaking specialist training with the Australian and New Zealand College of Anaesthetists. He undertook postgraduate medical training at Royal North Shore Hospital and graduated from The University of Sydney with the degrees of Bachelor of Applied Science (Physiotherapy), Bachelor of Medicine, and Bachelor of Surgery. Ruilong Zhao, MD, $\mathbf{P h D}$, is a Junior Medical Officer at Royal North Shore Hospital. Albert Kim, MD, BMed, is an Intensive Care Medicine Registrar at Royal North Shore Hospital. Aruna Wijewardena, MBBS, is a Burns Surgeon at Royal North Shore Hospital.
John Vandervord, MBBS, FRCS, is the former Director of Surgery and the former Director of Burns, Reconstructive and Plastic Surgery at Royal North Shore Hospital. He has been a specialist burns surgeon for over four decades. Meilang Xue, PhD, is an Associate Professor with the University of Sydney and the Kolling Institute and specializes in cell biology and immunology. Christopher John Jackson, BAppSc, MAppSc, PhD, is Professor of Regenerative Science and Medicine at The University of Sydney and the Director of the Sutton Laboratories in the Kolling Institute. He has a special interest in the role of $\mathrm{PC}$ in wound healing.

\section{REFERENCES}

1. Peck M. Epidemiology of burns throughout the world. Part l: distribution and risk factors. Burns 2011;37:1087-1100

2. Taylor SL, Sen S, Greenhalgh DG, Lawless M, Curri T, Palmieri TL. A competing risk analysis for hospital length of stay in patients with burns. JAMA Surg 2015;150:450-456.

3. Santos JV, Oliveira A, Costa-Pereira A, Amarante $\mathrm{J}$, Freitas A. Burden of burns in Portugal, 2000-2013: a clinical and economic analysis of 26,447 hospitalisations. Burns 2016;42:891-900.

4. Strassle PD, Williams FN, Napravnik S, et al. Improved survival of patients with extensive burns: trends in patient characteristics and mortality among burn patients in a tertiary care burn facility 2004-2013. J Burn Care Res 2017;38:187-193.

5. Asaria P, Elliott $P$, Douglass $M$, et al. Acute myocardial infarction hospital admissions and deaths in England: a national follow-back and follow-forward record-linkage study. Lancet Public Health 2017;2:e191-e201.

6. Giri S, Pathak R, Aryal MR, Karmacharya P, Bhatt VR, Martin MG. Lack of "weekend effect" on mortality for pulmonary embolism admissions in 2011: data from nationwide inpatient sample. Int J Cardiol 2015;180:151-153.

7. Sydnenham. On the treatment of burns. Lancet 1844;43:153.

8. Sneve H. The treatment of burns and skin grafting. J Am Med Assoc 1905;45:1-8.

9. Hettiaratchy S, Dziewulski P. ABC of burns: pathophysiology and types of burns. BMJ 2004; 328:1427-1429.

10. Jackson DM. The diagnosis of the depth of burning. Br J Surg 1953;40:588-596.

11. Schmauss D, Machens H-G, Harder $Y$, Finck T, Rezaeian $F$, Wettstein $R$. Treatment of secondary burn wound progression in contact burns-a systematic review of experimental approaches. $\mathrm{J}$ Burn Care Res 2015;36:e176-e189.

12. Abadie S, Jardet C, Colombelli J, et al. 3D imaging of cleared human skin biopsies using lightsheet microscopy: a new way to visualize indepth skin structure. Skin Res Technol 2018;24: 294-303.

13. Rowan MP, Cancio LC, Elster EA, et al. Burn wound healing and treatment: review and advancements. Crit Care 2015;19:243.

14. Porter C, Tompkins RG, Finnerty CC, Sidossis LS, Suman $\mathrm{OE}$, Herndon DN. The metabolic stress response to burn trauma: current understanding and therapies. Lancet 2016;388:1417-1426.

15. Finnerty CC, Jeschke MG, Branski LK, Barret JP, Dziewulski P, Herndon DN. Hypertrophic scarring: the greatest unmet challenge after burn injury. Lancet 2016;388:1427-1436.

16. Enkhbaatar P, Pruitt BA, Jr., Suman 0 , et al. Pathophysiology, research challenges, and clinical management of smoke inhalation injury. Lancet 2016;388:1437-1446.

17. Anderson TA, Fuzaylov G. Perioperative anesthesia management of the burn patient. Surg Clin North Am 2014;94:851-861.

18. Zuo KJ, Medina A, Tredget EE. Important developments in burn care. Plast Reconstr Surg 2017;139:120e-138e

19. Guilabert P, Usúa G, Martín N, Abarca L, Barret $J P$, Colomina MJ. Fluid resuscitation management in patients with burns: update. $\mathrm{Br} \mathrm{J} \mathrm{An}$ aesth 2016;117:284-296.

20. Kim A, Lang T, Xue M, Wijewardana A, Jackson C, Vandervord J. The role of Th-17 cells and $\gamma \delta$ T-cells in modulating the systemic inflammatory response to severe burn injury. Int $\mathrm{J} \mathrm{Mol} \mathrm{Sci}$ 2017;18:758

21. Nikolinakos PG, Altorki N, Yankelevitz D, et al. Plasma cytokine and angiogenic factor profiling identifies markers associated with tumor shrinkage in early-stage non-small cell lung cancer patients treated with pazopanib. Cancer Res 2010;70:2171-2179

22. Zahran S, Hamed E, Awean GA, Abdel-Hafez N, Hassan Y. Pediatric burn and key regulatory cytokines: impact of burn surface area and sepsis on the clinical outcomes. J Pediatr Biochem 2010;1:279-288.

23. Shelhamer MC, Rowan MP, Cancio LC, et al Elevations in inflammatory cytokines are associated with poor outcomes in mechanically ventilated burn patients. J Trauma Acute Care Surg 2015;79:431-436

24. Marik PE, Flemmer M. The immune response to surgery and trauma: implications for treatment. $J$ Trauma Acute Care Surg 2012;73:801-808.

25. Rani M, Zhang 0 , Schwacha MG. Burn wound $\gamma \delta$ T-cells support a Th2 and Th17 immune response. J Burn Care Res 2014;35:46-53.

26. Sasaki JR, Zhang 0, Schwacha MG. Burn induces a Th-17 inflammatory response at the injury site. Burns 2011;37:646-651.

27. Zedler $S$, Bone $R C$, Baue $A E$, von Donnersmarck $\mathrm{GH}$, Faist E. T-cell reactivity and its predictive role in immunosuppression after burns. Crit Care Med 1999:27:66-72.

28. Hampson P, Dinsdale RJ, Wearn CM, et al. Neutrophil dysfunction, immature granulocytes, and cell-free DNA are early biomarkers of sepsis in burn-injured patients: a prospective observational cohort study. Ann Surg 2017;265:1241-1249.

29. Altmann DM. The immune regulatory role of neutrophils. Immunology 2019;156:215-216

30. Gupta S, Chan DW, Zaal KJ, Kaplan MJ. A highthroughput real-time imaging technique to quantify NETosis and distinguish mechanisms of cell death in human neutrophils. J Immunol 2018;200:869-879. 
31. Schwacha MG. $\gamma \delta$ T-cells: potential regulators of the post-burn inflammatory response. Burns 2009:35:318-326.

32. Schwacha MG, Daniel T. Up-regulation of cell surface Toll-like receptors on circulating $\gamma \delta$ Tcells following burn injury. Cytokine 2008;44: 328-334.

33. Bucy RP, Chen CL, Cooper MD. Tissue localization and CD8 accessory molecule expression of $\mathrm{T}$ gamma delta cells in humans. J Immunol 1989; 142:3045-3049.

34. Rani $M$, Zhang 0 , Scherer MR, Cap AP, Schwacha MG. Activated skin $\gamma \delta$ T-cells regulate T-cell infiltration of the wound site after burn. Innate Immun 2015;21:140-150.

35. Finnerty CC, Herndon DN, Chinkes DL, Jeschke MG. Serum cytokine differences in severely burned children with and without sepsis. Shock 2007;27:4-9.

36. Arslan E, Yavuz M, Dalay C. The relationship between tumor necrosis factor (TNF)-alpha and survival following granulocyte-colony stimulating factor (G-CSF) administration in burn sepsis. Burns 2000;26:521-524.

37. Finnerty CC, Herndon DN, Przkora R, et al. Cytokine expression profile over time in severly burned pediatric patients. Shock 2006;26:13-19.

38. Jeschke MG, Finnerty CC, Kulp GA, Kraft R, Herndon DN. Can we use C-reactive protein levels to predict severe infection or sepsis in severely burned patients? Int J Burns Trauma 2013;3:137-143.

39. Kraft R, Herndon DN, Finnerty CC, Cox RA, Song J, Jeschke MG. Predictive value of IL-8 for sepsis and severe infections after burn injury: a clinical study. Shock 2015;43:222-227.

40. Finnerty CC, Jeschke MG, Qian WJ, et al. Determination of burn patient outcome by largescale quantitative discovery proteomics. Crit Care Med 2013;41:1421-1434.

41. Mandrup-Poulsen $T$, Wogensen LD, Jensen $M$, et al. Circulating interleukin-1 receptor antagonist concentrations are increased in adult patients with thermal injury. Crit Care Med 1995;23:26-33.

42. Pugin J, Widmer MC, Kossodo S, Liang CM, Preas HLn, Suffredini AF. Human neutrophils secrete gelatinase $B$ in vitro and in vivo in response to endotoxin and proinflammatory mediators. Am J Respir Cell Mol Biol 1999;20:458464.

43. Sternlicht MD, Werb Z. How matrix metalloproteinases regulate cell behavior. Annu Rev Cell Dev Biol 2001;17:463-516.

44. Visse R, Nagase H. Matrix metalloproteinases and tissue inhibitors of metalloproteinases: structure, function, and biochemistry. Circ Res 2003;92:827-839.

45. Nagy B, Szelig L, Rendeki S, et al. Dynamic changes of matrix metalloproteinase 9 and tissue inhibitor of metalloproteinase 1 after burn injury. J Crit Care 2015;30:162-166.
46. Hastbacka J, Freden F, Hult M, et al. Matrix metalloproteinases- 8 and -9 and tissue inhibitor of metalloproteinase-1 in burn patients. A prospective observational study. PLoS One 2015;10: e0125918.

47. Huang L, Yao Y, Dong N, et al. Prognostic significance of plasma gelsolin in severe burn patients with sepsis [in Chinese]. Zhonghua Shao Shang Za Zhi 2016;32:77-81.

48. Jeschke MG, Gauglitz GG, Kulp GA, et al. Longterm persistance of the pathophysiologic response to severe burn injury. PLoS One 2011;6: e21245.

49. Patsouris D, Qi P, Abdullahi A, et al. Burn induces browning of the subcutaneous white adipose tissue in mice and humans. Cell Rep 2015; 13:1538-1544.

50. Sidossis LS, Porter C, Saraf MK, et al. Browning of subcutaneous white adipose tissue in humans after severe adrenergic stress. Cell Metab 2015; 22:219-227.

51. Wilmore DW, Aulick LH. Systemic responses to injury and the healing wound. JPEN J Parenter Enteral Nutr 1980;4:147-151.

52. Biolo G, Fleming RY, Maggi SP, Nguyen TT, Herndon DN, Wolfe RR. Inverse regulation of protein turnover and amino acid transport in skeletal muscle of hypercatabolic patients. J Clin Endocrinol Metab 2002;87:3378-3384.

53. Tzika AA, Mintzopoulos D, Mindrinos M, Zhang J, Rahme LG, Tompkins RG. Microarray analysis suggests that burn injury results in mitochondrial dysfunction in human skeletal muscle. Int $\mathrm{J} \mathrm{Mol}$ Med 2009;24:387-392.

54. Yu YM, Tompkins RG, Ryan CM, Young VR. The metabolic basis of the increase of the increase in energy expenditure in severely burned patients. JPEN J Parenter Enteral Nutr 1999;23: 160-168.

55. Cree MG, Zwetsloot JJ, Herndon DN, et al. Insulin sensitivity and mitochondrial function are improved in children with burn injury during a randomized controlled trial of fenofibrate. Ann Surg 2007;245:214-221.

56. Wolfe RR, Jahoor F, Herndon DN, Miyoshi H. Isotopic evaluation of the metabolism of pyruvate and related substrates in normal adult volunteers and severely burned children: effect of dichloroacetate and glucose infusion. Surgery 1991;110:54-67.

57. Sun C, Sun L, Ma H, et al. The phenotype and functional alterations of macrophages in mice with hyperglycemia for long term. J Cell Physiol 2012;227:1670-1679.

58. Brauner H, Luthje P, Grunler J, et al. Markers of innate immune activity in patients with type 1 and type 2 diabetes mellitus and the effect of the anti-oxidant coenzyme 010 on inflammatory activity. Clin Exp Immunol 2014;177:478-482.

59. Zang ZD, Yan Z, Hui JJ, Yan J, Chen HY. Prognostic significance of mean amplitude of glycemic excursion in patients with severe burn [ in
Chinese]. Zhonghua Shao Shang Za Zhi 2016;32: 35-39.

60. Osuka A, Kusuki H, Yoneda K, et al. Glycocalyx shedding is enhanced by age and correlates with increased fluid requirement in patients with major burns. Shock 2018;50:60-65.

61. Lavrentieva A, Kontakiotis T, Bitzani M, et al. Early coagulation disorders after severe burn injury: impact on mortality. Intensive Care Med 2008;34:700-706.

62. Mosnier LO, Zlokovic BV, Griffin JH. The cytoprotective protein $C$ pathway. Blood 2007;109: 3161-3172.

63. Xue M, Campbell D, Jackson CJ. Protein C is an autocrine growth factor for human skin keratinocytes. J Biol Chem 2007;282:13610-13616.

64. Pina-Canseco MS, Páez-Arenas A, Massó F, et al. Protein $C$ activation peptide inhibits the expression of ICAM-1, VAM-1, and interleukin-8 induced by TNF- $\alpha$ in human dermal microvascular endothelial cells. Folia Histochem Cytobiol 2012;50:407-413.

65. Esmon CT. Protein C anticoagulant systemanti-inflammatory effects. Semin Immunopathol 2012;34:127-132.

66. Whitmont K, Fulcher G, Reid I, et al. Low circulating protein $C$ levels are associated with lower leg ulcers in patients with diabetes. Biomed Res Int 2013;2013: 719570.

67. Whitmont K, Reid I, Tritton S, et al. Treatment of chronic leg ulcers with topical activated protein C. Arch Dermatol 2008;144:1479-1483.

68. Jackson CJ, Xue M. Activated protein C: an anticoagulant that does more than stop clots. Int J Biochem Cell Biol 2008;40:2692-2697.

69. Jackson C, Whitmont K, Tritton S, March L, Sambrook P, Xue M. New therapeutic applications for the anticoagulant, activated protein $\mathrm{C}$. Expert Opin Biol Ther 2008;8:1109-1122.

70. Whitmont K, McKelvey KJ, Fulcher G, et al. Treatment of chronic diabetic lower leg ulcers with activated protein $\mathrm{C}$ : A randomised placebocontrolled, double-blind pilot clinical trial. Int Wound J 2015;12:422-427.

71. Wijewardena A, Vandervord E, Lajevardi SS, Vandervord J, Jackson CJ. Combination of activated protein $C$ and topical negative pressure rapidly regenerates granulation tissue over exposed bone to heal recalcitrant orthopedic wounds. Int J Low Extrem Wounds 2011;10: 146-151.

72. Wijewardena A, Lajevardi SS, Vandervord $E_{1}$ et al. Activated protein $C$ to heal pressure ulcers. Int Wound J 2016;13:986-991.

73. Minhas N, Xue M, Fukudome K, Jackson CJ. Activated protein $\mathrm{C}$ utilizes the angiopoietin/Tie2 axis to promote endothelial barrier function. FASEB J 2010;24:873-881.

74. Lo SCL, Lai WT, Kwok F. Protein C and protein S levels in some burn patients. Burns 1994;20: 186-187. 
75. Esechie A, Enkhbaatar P, Nakano YY, Traber L, Herndon D, Traber DL. Comparison of plasma concentrations of antithrombin (AT) and protein c $(\mathrm{PC})$ in burn and smoke inhalation injury and sepsis. FASEB J 2006;20:A286-A287.

76. Lang T, Kim A, Wijewardena A, et al. Circulating protein $C$ levels in severe burns. Australian and New Zealand Burns Association Annual Scientific Meeting. Adelaide, 2017.

77. Nawroth PP, Stern DM. Modulation of endothelial cell hemostatic properties by tumor necrosis factor. J Exp Med 1986;163:740-745

78. Yamamoto K, Shimokawa T, Kojima T, Loskutoff DJ, Saito H. Regulation of murine protein $\mathrm{C}$ gene expression in vivo: effects of tumor necrosis factor-alpha, interleukin-1, and transforming growth factor-beta. Thromb Haemost 1999;82: 1297-1301.

79. Tejiram S, Brummel-Ziedins KE, Orfeo T, et al. Indepth analysis of clotting dynamics in burn patients. J Surg Res 2016;202:341-351.

80. Advanced trauma life support (ATLS): the ninth edition. J Trauma Acute Care Surg 2013;74: 1363-1366.

81. Giretzlehner M, Dirnberger J, Owen R, Haller HL, Lumenta DB, Kamolz LP. The determination of total burn surface area: how much difference? Burns 2013;39:1107-1113.

82. Harvey JS, Watkins GM, Sherman RT. Emergent burn care. South Med J 1984;77:204-214.

83. Goldberg H, Klaff J, Spjut A, Milner S. A mobile app for measuring the surface area of a burn in three dimensions: comparison to the Lund and Browder assessment. J Burn Care Res 2014;35: 480-483.

84. Brunicardi FC, Andersen DK, Billiar TR, Dunn DL, Hunter JG, Pollock RE. Schwartz's Principles of Surgery, 8th ed. New York, NY: McGraw Hill Medical Publication Division, 2004.

85. Israel JS, Greenhalgh DG, Gibson AL. Variations in burn excision and grafting: a survey of the American Burn Association. J Burn Care Res 2017;38:e125-e132.

86. Pan BS, Vu AT, Yakuboff KP. Management of the acutely burned hand. J Hand Surg 2015;40: 1477-1484; quiz 85.

87. Monstrey S, Hoeksema H, Verbelen J, Pirayesh A, Blondeel P. Assessment of burn depth and burn wound healing potential. Burns 2008;34: 761-769.

88. Watts AM, Tyler MP, Perry ME, Roberts AH, McGrouther DA. Burn depth and its histological measurement. Burns 2001;27:154-160.

89. Devgan L, Bhat S, Aylward S, Spence RJ. Modalities for the assessment of burn wound depth. J Burns Wounds 2006;5:e2.

90. Tocco-Tussardi I, Presman B, Huss F. Want correct percentage of TBSA burned? Let a layman do the assessment. J Burn Care Res 2018;39:295-301.

91. Ching JA, Shah JL, Doran CJ, Chen H, Payne WG, Smith DJ, Jr. The evaluation of physical exam findings in patients assessed for suspected burn inhalation injury. J Burn Care Res 2015;36: 197-202.

92. Kim Y, Kym D, Hur J, et al. Does inhalation injury predict mortality in burns patients or require redefinition? PLoS One 2017;12:e0185195.

93. Aung MT, Garner D, Pacquola M, et al. The use of a simple three-level bronchoscopic assessment of inhalation injury to predict in-hospital mortality and duration of mechanical ventilation in patients with burns. Anaesth Intensive Care 2018;46:67-73.

94. Baux S, Mimoun M, Saade H, et al. Burns in the elderly. Burns 1989;15:239-240.

95. Zawacki BE, Azen SP, Imbus SH, Chang YTC. Multifactorial probit analysis of mortality in burned patients. Ann Surg 1979;189:1-5.

96. Tobiasen J, Hiebert JM, Edlich RF. The abbreviated burn severity index. Ann Emerg Med 1982;11:260-262.

97. Roi LD, Flora JD, Davis TM, Wolfe RA. Two new burn severity indices. J Trauma 1983;23:10231029 .

98. Hussain A, Dunn KW. Predicting length of stay in thermal burns: a systematic review of prognostic factors. Burns 2013;39:1331-1340.

99. Hop MJ, Stekelenburg CM, Hiddingh J, et al. Costeffectiveness of laser doppler imaging in burn care in the netherlands: a randomized controlled trial. Plast Reconstr Surg 2016;137:166e-176e.

100. Jan SN, Khan FA, Bashir MM, et al. Comparison of Laser Doppler Imaging (LDI) and clinical assessment in differentiating between superficial and deep partial thickness burn wounds. Burns 2018;44:405-413.

101. Elmasry M, Mirdell R, Tesselaar E, Farnebo S, Sjoberg F, Steinvall I. Laser speckle contrast imaging in children with scalds: its influence on timing of intervention, duration of healing and care, and costs. Burns 2019. [Epub ahead of print]; DOI: 10.1016/j.burns.2019.02.001.

102. Ponticorvo A, Rowland R, Baldado M, et al. Evaluating clinical observation versus Spatial Frequency Domain Imaging (SFDI), Laser Speckle Imaging (LSI) and thermal imaging for the assessment of burn depth. Burns 2019;45:450-460.

103. Ida T, Iwazaki H, Kawaguchi Y, et al. Burn depth assessments by photoacoustic imaging and laser Doppler imaging. Wound Repair Regen 2016;24: 349-355.

104. Jaspers MEH, van Haasterecht $L$, van Zuijlen PPM, Mokkink LB. A systematic review on the quality of measurement techniques for the assessment of burn wound depth or healing potential. Burns 2019;45:261-281.

105. Seki T, Fujioka M, Fukushima $H$, et al. Regional tissue oxygen saturation measured by nearinfrared spectroscopy to assess the depth of burn injuries. Int J Burns Trauma 2014;4:40-44.

106. Andrews C, Kempf M, Kimble R, Cuttle L. How do skin thickness measurements obtained via ultrasound compare to histologically determined values? Australian and New Zealand Burns Association Annual Scientific Meeting, Adelaide, 2017.

107. Burmeister DM, Cerna C, Becerra SC, Sloan M, Wilmink G, Christy RJ. Noninvasive techniques for the determination of burn severity in real time. J Burn Care Res 2017;38:e180-e191.

108. Jaskille $A D$, Shupp JW, Jordan MH, Jeng JC Critical review of burn depth assessment techniques: Part I. Historical review. J Burn Care Res 2009;30:937-947.

109. Kaiser M, Yafi A, Cinat M, Choi B, Durkin AJ. Noninvasive assessment of burn wound severity using optical technology: a review of current and future modalities. Burns 2011;37:377-386.

110. Kamolz L-P, Parvizi D, Lumenta DB. The use of Indocyanine green dye angiography in burns. Burns 2014;40:776-777.

111. Wongkietkachorn A, Surakunprapha P, Winaikosol K, et al. Indocyanine green dye angiography as an adjunct to assess indeterminate burn wounds: a prospective, multi-centered, tripleblinded study. J Trauma Acute Care Surg 2019; 86:823-828.

112. Rosenberg AS. Reconsidering the H\&E stain as the gold standard in assessing the depth of burn wounds. J Cutan Pathol 2017;44:1049-1050.

113. Xiao M, Li L, Li C, et al. Role of autophagy and apoptosis in wound tissue of deep seconddegree burn in rats. Acad Emerg Med 2014;21: 383-391.

114. Kazlouskaya V, Malhotra S, Lambe J, Idriss MH, Elston D, Andres C. The utility of elastic Verhoeff-Van Gieson staining in dermatopathology. J Cutan Pathol 2013;40:211-225.

115. Nanney LB, Wenczak BA, Lynch JB. Progressive burn injury documented with vimentin immunostaining. J Burn Care Rehabil 1996;17:191-198.

116. Environmental health criteria 222 biomarkers in risk assessment: validity and validation. World Health Organization, 2001. www.inchem.org/ documents/ehc/ehc/ehc222.htm (last accessed April 18, 2018).

117. Gupta K, Mehrotra M, Kumar P, Gogia AR, Prasad A, Fisher JA. Smoke inhalation injury: etiopathogenesis, diagnosis, and management. Indian J Crit Care Med 2018;22:180-188.

118. Allan PF, Osborn EC, Chung KK, Wanek SM. High-frequency percussive ventilation revisited. J Burn Care Res 2010;31:510-520.

119. Miller AC, Ferrada PA, Kadri SS, NatarajBhandari K, Vahedian-Azimi A, Quraishi SA High-frequency ventilation modalities as salvage therapy for smoke inhalation-associated acute lung injury: a systematic review. J Intensive Care Med 2018;33:335-345.

120. McGinn KA, Weigartz K, Lintner A, Scalese MJ, Kahn SA. Nebulized heparin with Nacetylcysteine and albuterol reduces duration of mechanical ventilation in patients with inhalation injury. J Pharm Pract 2019;32:163-166. 
121. Elsharnouby NM, Eid HE, Abou Elezz NF, Aboelatta YA. Heparin/N-acetylcysteine: an adjuvant in the management of burn inhalation injury: a study of different doses. J Crit Care 2014;29: 182.e1-182.e4.

122. Kowal-Vern A, Orkin BA. Antithrombin in the treatment of burn trauma. World J Crit Care Med 2016;5:17-26.

123. Fauntleroy AM, Hoagland AW. The treatment of burns: as exemplified in thirty-two cases. Ann Surg 1919;69:589-595.

124. Baxter CR, Shires T. Physiological response to crystalloid resuscitation of severe burns. Ann N Y Acad Sci 1968;150:874-894.

125. Baker RHJ, Akhavani MA, Jallali N. Resuscitation of thermal injuries in the United Kingdom and Ireland. J Plast Reconstr Aesthet Surg 2007; 60:682-685.

126. Gordon M, Marvin J, Greenfield E, et al. Regional and institutional variation in burn care. J Burn Care Rehabil 1995;16:85-90.

127. Engrav LH, Colescott PL, Kemalyan N, et al. A biopsy of the use of the Baxter formula to resuscitate burns or do we do it like Charlie did it? J Burn Care Rehabil 2000;21:91-95.

128. Cartotto RC, Innes M, Musgrave MA, Gomez M, Cooper AB. How well does the Parkland formula estimate actual fluid resuscitation volumes? J Burn Care Rehabil 2002;23:258-265.

129. Friedrich JB, Sullivan SR, Engrav LH, et al. Is supra-Baxter resuscitation in burn patients a new phenomenon? Burns 2004;30:464-466.

130. Pham TN, Cancio LC, Gibran NS. American Burn Association practice guidelines burn shock resuscitation. J Burn Care Res 2008;29:257-266.

131. Haberal M, Abali AES, Karakayali H. Fluid management in major burn injuries. Indian $\mathrm{J}$ Plast Surg 2010;43:S29.

132. Chung KK, Salinas J, Renz EM, et al. Simple derivation of the initial fluid rate for the resuscitation of severely burned adult combat casualties: in silico validation of the rule of $10 . \mathrm{J}$ Trauma 2010;69(Suppl 1):S49-S54.

133. Borden Institute. Burns. In: Cubano MA, ed. Emergency War Surgery, 5th ed. Fort Sam Houston, TX: Borden Institute US Army Medical Department Center and School, 2015.

134. Renz EM, Cancio LC. Acute burn care. In: Borden Institute, ed. Combat Casualty Care. Falls Church, VA: Office of the Surgeon General, 2012: 593-638.

135. Ivy ME, Atweh NA, Palmer J, Possenti PP, Pineau M, D'Aiuto M. Intra-abdominal hypertension and abdominal compartment syndrome in burn patients. J Trauma 2000;49:387-391.

136. Klein MB, Hayden D, Elson C, et al. The association between fluid administration and outcome following major burn: a multicenter study. Ann Surg 2007;245:622-628.

137. Oda J, Yamashita K, Inoue T, et al. Resuscitation fluid volume and abdominal compartment syn- drome in patients with major burns. Burns 2006; 32:151-154.

138. Brandstrup B, Tønnesen $H$, Beier-Holgersen $R$, et al. Effects of intravenous fluid restriction on postoperative complications: comparison of two perioperative fluid regimens: a randomized assessor-blinded multicenter trial. Ann Surg 2003;238:641.

139. Cortés DO, Barros TG, Njimi H, Vincent J-L. Crystalloids versus colloids: exploring differences in fluid requirements by systematic review and metaregression. Anesth Analg 2015;120:389-402.

140. Zarychanski R, Abou-Setta AM, Turgeon AF, et al. Association of hydroxyethyl starch administration with mortality and acute kidney injury in critically ill patients requiring volume resuscitation: a systematic review and meta-analysis. JAMA 2013;309:678-688.

141. Cooper $A B$, Cohn SM, Zhang HS, et al. Five percent albumin for adult burn shock resuscitation: lack of effect on daily multiple organ dysfunction score. Transfusion 2006;46:80-89.

142. Cochran A, Morris SE, Edelman LS, Saffle JR. Burn patient characteristics and outcomes following resuscitation with albumin. Burns 2007; 33:25-30.

143. Park SH, Hemmila MR, Wahl WL. Early albumin use improves mortality in difficult to resuscitate burn patients. J Trauma Acute Care Surg 2012; 73:1294-1297.

144. O'Mara MS, Slater H, Goldfarb IW, Caushaj PF. A prospective, randomized evaluation of intraabdominal pressures with crystalloid and colloid resuscitation in burn patients. J Trauma 2005;58: 1011-1018.

145. Du G-b, Slater H, Goldfarb IW. Influences of different resuscitation regimens on acute early weight gain in extensively burned patients. Burns 1991;17:147-150.

146. Hoelscher V, Harvin J, Cotton B, Wade C, Huzar T. 218 Impact of fresh frozen plasma infusions during resuscitation in thermally-injured patients. J Burn Care Res 2018;39:S76.

147. Jones LM, Deluga N, Bhatti P, Scrape SR, Bailey JK, Coffey RA. TRALI following fresh frozen plasma resuscitation from burn shock. Burns 2017:43:397-402.

148. Cartotto R, Greenhalgh D. Colloids in acute burn resuscitation. Crit Care Clin 2016;32:507-523.

149. Jones L, Brown N, Philips G, et al. Burn resuscitation with fresh frozen plasma: 5 years of experience with the west Penn formula. Austn J Emerg Crit Care Med 2015;2:1018.

150. Berger MM, Bernath M-A, Chioléro RL. Resuscitation, anaesthesia and analgesia of the burned patient. Curr Opin Anesthesiol 2001;14:431-435.

151. Holm C, Melcer B, Horbrand F, Worl H, von Donnersmarck GH, Muhlbauer W. Intrathoracic blood volume as an end point in resuscitation of the severely burned: an observational study of 24 patients. J Trauma 2000;48:728-734.
152. Holm C, Melcer B, Horbrand F, von Donnersmarck GH, Muhlbauer W. Arterial thermodilution: an alternative to pulmonary artery catheter for cardiac output assessment in burn patients. Burns 2001:27:161-166.

153. Kuntscher MV, Blome-Eberwein S, Pelzer $M$, Erdmann D, Germann G. Transcardiopulmonary vs pulmonary arterial thermodilution methods for hemodynamic monitoring of burned patients. J Burn Care Rehabil 2002;23:21-26.

154. Tokarik M, Sjoberg F, Balik M, Pafcuga I, Broz L. Fluid therapy LiDCO controlled trial-optimization of volume resuscitation of extensively burned patients through noninvasive continuous realtime hemodynamic monitoring LiDCO. J Burn Care Res 2013;34:537-542.

155. Monnet X, Teboul J-L. Transpulmonary thermodilution: advantages and limits. Crit Care 2017; 21:147.

156. Reuter DA, Felbinger TW, Moerstedt K, et al. Intrathoracic blood volume index measured by thermodilution for preload monitoring after cardiac surgery. J Cardiothorac Vasc Anesth 2002; 16:191-195.

157. Bittner EA, Shank E, Woodson L, Martyn JA. Acute and perioperative care of the burn-injured patient. Anesthesiology 2015;122:448-464.

158. Holm C, Melcer B, Horbrand F, Worl HH, von Donnersmarck GH, Muhlbauer W. Haemodynamic and oxygen transport responses in survivors and non-survivors following thermal injury. Burns 2000;26:25-33.

159. Aboelatta Y, Abdelsalam A. Volume overload of fluid resuscitation in acutely burned patients using transpulmonary thermodilution technique. J Burn Care Res 2013;34:349-354.

160. Csontos C, Foldi V, Fischer T, Bogar L. Arterial thermodilution in burn patients suggests a more rapid fluid administration during early resuscitation. Acta Anaesthesiol Scand 2008;52:742-749.

161. Matsuda T, Tanaka H, Shimazaki S, et al. Highdose vitamin $C$ therapy for extensive deep dermal burns. Burns 1992;18:127-131.

162. Kremer T, Harenberg P, Hernekamp F, et al. Highdose vitamin C treatment reduces capillary leakage after burn plasma transfer in rats. $\mathrm{J}$ Burn Care Res 2010;31:470-479.

163. Cartotto R, Greenhalgh DG, Cancio C. Burn state of the science: fluid resuscitation. $J$ Burn Care Res 2017;38:e596-e604.

164. Mann R, Foster K, Kemalyan N, Gibran N, Engrav L, Heimbach D. Intravenous vitamin C in clinical burn resuscitation. J Burn Care Rehabil 1997;29:S87.

165. Tanaka H, Matsuda T, Miyagantani Y, Yukioka T, Matsuda $\mathrm{H}$, Shimazaki S. Reduction of resuscitation fluid volumes in severely burned patients using ascorbic acid administration: a randomized, prospective study. Arch Surg 2000;135:326-331.

166. Kahn SA, Beers RJ, Lentz CW. Resuscitation after severe burn injury using high-dose ascorbic acid: a retrospective review. J Burn Care Res 2011:32:110-117. 
167. Buehner M, Pamplin J, Studer L, et al. Oxalate nephropathy after continuous infusion of highdose vitamin $C$ as an adjunct to burn resuscitation. J Burn Care Res 2016;37:e374-e379.

168. Kahn SA, Lentz CW. Fictitious hyperglycemia: point-of-care glucose measurement is inaccurate during high-dose vitamin $C$ infusion for burn shock resuscitation. J Burn Care Res 2015;36: e67-e71.

169. Schlader ZJ, Vargas NT. Regulation of Body Temperature by Autonomic and Behavioral Thermoeffectors. Exerc Sport Sci Rev 2019;47:116-126.

170. Shapiro Y, Epstein Y, Ben-Simchon C, Tsur H. Thermoregulatory responses of patients with extensive healed burns. J Appl Physiol 1982;53: 1019-1022.

171. Ehrl D, Heidekrueger PI, Rubenbauger J, Ninkovic M, Broer PN. Impact of prehospital hypothermia on the outcomes of severely burned patients. $J$ Burn Care Res 2018;39:739-743.

172. Weaver MD, Rittenberger JC, Patterson PD, et al. Risk factors for hypothermia in EMStreated burn patients. Prehosp Emerg Care 2014; 18:335-341.

173. Gerecht R. The lethal triad. Hypothermia, acidosis \& coagulopathy create a deadly cycle for trauma patients. JEMS 2014;39:56-60.

174. Singer AJ, Taira BR, Thode HC, Jr., et al. The association between hypothermia, prehospital cooling, and mortality in burn victims. Acad Emerg Med 2010;17:456-459.

175. Singer AJ, Wang E, Taira BR, Steinhauff N, Rooney J, Zimmerman T. Controlled mild hypothermia prolongs survival in a rat model of large scald burns. Acad Emerg Med 2011;18:287-291.

176. Tan N, Thode Jr HC, Singer AJ. The effect of controlled mild hypothermia on large scald burns in a resuscitated rat model. Clin Exp Emerg Med 2014;1:56

177. Ofeigsson OJ, Mitchell R, Patrick RS. Observations on the cold water treatment of cutaneous burns. J Pathol 1972;108:145-150.

178. Jackson D, Stone P. Tangential excision and grafting of burns: the method, and a report of 50 consecutive cases. Br J Plast Surg 1972;25:416426.

179. Loo YL, Goh BKL, Jeffery S. An overview of the use of bromelain-based enzymatic debridement [Nexobrid(R)] in deep partial and full thickness burns: appraising the evidence. J Burn Care Res 2018;39:932-938.

180. Schulz A, Fuchs PC, Hans N, Oplander C, Valdez LB, Schiefer JL. Inhibition of bromelain activity during enzymatic debridement of burn wounds pretreated with frequently used products. J Burn Care Res 2018:39:413-422.

181. Kakagia DD, Karadimas EJ. The efficacy of Versajet hydrosurgery system in burn surgery. A systematic review. J Burn Care Res 2018:39:188-200.

182. Mastroianni M, Ng ZY, Goyal R, et al. Topical delivery of immunosuppression to prolong $\mathrm{xe}$ - nogeneic and allogeneic split-thickness skin graft survival. J Burn Care Res 2018;39:363-373.

183. Pripotnev S, Papp A. Split thickness skin graft meshing ratio indications and common practices. Burns 2017:43:1775-1781.

184. Kagan RJ, Peck MD, Ahrenholz DH, et al. Surgical management of the burn wound and use of skin substitutes: an expert panel white paper. J Burn Care Res 2013;34:e60-e79.

185. Puri V, Khare NA, Chandramouli MV, Shende N, Bharadwaj S. Comparative analysis of early excision and grafting vs delayed grafting in burn patients in a developing country. J Burn Care Res 2016;37:278-282.

186. Engrav L, Heimbach D, Reus J, Harnar T, Marvin $J$. Early excision and grafting vs. nonoperative treatment of burns of indeterminant depth: a randomized prospective study. J Trauma Acute Care Surg 1983;23:1001-1004.

187. Heimbach DM. Early burn excision and grafting Surg Clin North Am 1987;67:93-107.

188. Toussaint J, Chung WT, Mc Clain S, Raut V Singer AJ. Optimal timing for early excision in a deep partial thickness porcine burn model. J Burn Care Res 2017;38:e352-e358.

189. Singer AJ, Toussaint J, Chung WT, McClain SA, Raut V, Rosenberg L. Early versus delayed excision and grafting of full-thickness burns in a porcine model: a randomized study. Plast Reconstr Surg 2016;137:972e-979e.

190. Ottomann C, Hartmann B, Branski L, Krohn C. A tribute to Cicero Parker Meek. Burns 2015;41 1660-1663.

191. Almodumeegh A, Heidekrueger PI, Ninkovic M, Rubenbauer J, Hadjipanayi E, Broer PN. The MEEK technique: 10-year experience at a tertiary burn centre. Int Wound J 2017;14:601-605.

192. Chong SJ, Choke A, Tan B-K. Technical tips to enhance micrografting results in burn surgery. Burns 2017:43:983-986.

193. Chua AWC, Khoo YC, Truong TTH, Woo E, Tan BK, Chong SJ. From skin allograft coverage to allograft-micrograft sandwich method: a retrospective review of severe burn patients who received conjunctive application of cultured epithelial autografts. Burns 2018;44:13021307.

194. Khalifian S, Brazio PS, Mohan R, et al. Facial transplantation: the first 9 years. Lancet 2014; 384:2153-2163.

195. Ng ZY, Lellouch AG, Drijkoningen $T$, Chang IA, Sachs DH, Cetrulo CL, Jr. Vascularized composite allotransplantation-an emerging concept for burn reconstruction. J Burn Care Res 2017; 38:371-378.

196. Ma T, Wang $X$, Jiang D. Immune tolerance of mesenchymal stem cells and induction of skin allograft tolerance. Curr Stem Cell Res Ther 2017;12:409-415.

197. Vyas KS, Burns C, Ryan DT, Wong L. Prolonged allograft survival in a patient with chronic im- munosuppression: a case report and systematic review. Wounds 2017:29:159-162.

198. Reilly DA, Hickey S, Glat P, Lineaweaver WC Goverman J. Clinical experience: using dehydrated human amnion/chorion membrane allografts for acute and reconstructive burn care. Ann Plast Surg 2017;78:S19-S26.

199. Lohana P, Hassan S, Watson SB. Integra ${ }^{\mathrm{TM}}$ in burns reconstruction: our experience and report of an unusual immunological reaction. Ann Burns Fire Disasters 2014;27:17-21.

200. Jackson SR, Roman S. Matriderm and split skin grafting for full-thickness pediatric facial burns. J Burn Care Res 2019;40:251-254.

201. Watt SM, Pleat JM. Stem cells, niches and scaffolds: applications to burns and wound care. Adv Drug Deliv Rev 2018;123:82-106.

202. Greenwood JE. The evolution of acute burn care-retiring the split skin graft. Ann R Coll Surg Engl 2017;99:432-438.

203. Boyce ST, Simpson PS, Rieman MT, et al. Randomized, paired-site comparison of autologous engineered skin substitutes and split-thickness skin graft for closure of extensive, full-thickness burns. J Burn Care Res 2017;38:61-70.

204. Klama-Baryla A, Kitala D, Labus W, et al. Autologous and allogeneic skin cell grafts in the treatment of severely burned patients: retrospective clinical study. Transplant Proc 2018;50: 2179-2187.

205. Varkey M, Visscher D0, van Zuijlen PPM, Atala A, Yoo JJ. Skin bioprinting: the future of burn wound reconstruction? Burns Trauma 2019;7:4.

206. Huang S, Yao B, Xie J, Fu X. 3D bioprinted extracellular matrix mimics facilitate directed differentiation of epithelial progenitors for sweat gland regeneration. Acta Biomater 2016;32:170177.

207. Novaes MA, Knobel E, Bork AM, Pavao OF, Nogueira-Martins LA, Ferraz MB. Stressors in ICU: perception of the patient, relatives and health care team. Intensive Care Med 1999;25: 1421-1426.

208. Woolf CJ, Mannion RJ. Neuropathic pain: aetiology, symptoms, mechanisms, and management. Lancet 1999;353:1959-1964.

209. Chapman CR, Tuckett RP, Song CW. Pain and stress in a systems perspective: reciprocal neural, endocrine, and immune interactions. J Pain 2008:9:122-145

210. Sneddon LU. Comparative physiology of nociception and pain. Physiology (Bethesda) 2018;33 63-73.

211. Tracey WD, Jr. Nociception. Curr Biol 2017;27 R129-R133.

212. Green D, Ruparel S, Gao X, et al. Central activation of TRPV1 and TRPA1 by novel endogenous agonists contributes to mechanical allodynia and thermal hyperalgesia after burn injury. Mol Pain 2016. [Epub ahead of print]; DOI: 10.1177/ 1744806916661725. 
213. de Jong AE, Bremer M, Schouten M, Tuinebreijer WE, Faber AW. Reliability and validity of the pain observation scale for young children and the visual analogue scale in children with burns. Burns 2005;31:198-204.

214. Taal LA, Faber AW. The burn specific pain anxiety scale: introduction of a reliable and valid measure. Burns 1997;23:147-150.

215. Gelinas C, Fillion L, Puntillo KA, Viens C, Fortier M. Validation of the critical-care pain observation tool in adult patients. Am J Crit Care 2006; 15:420-427.

216. Faucher L, Furukawa K. Practice guidelines for the management of pain. J Burn Care Res 2006; 27:659-668.

217. Richardson P, Mustard L. The management of pain in the burns unit. Burns 2009;35:921-936.

218. Tully A, Anderson L, Adams W, Mosier MJ. Opioid creep in burn center discharge regimens: doubled amounts and complexity of narcotic prescriptions over seven years. Burns 2019;45:328-334.

219. Basurto Ona X, Rigau Comas D, Urrutia G. Opioids for acute pancreatitis pain. Cochrane Database Syst Rev 2013;7:CD009179.

220. Pathan SA, Mitra B, Cameron PA. A systematic review and meta-analysis comparing the efficacy of nonsteroidal anti-inflammatory drugs, opioids, and paracetamol in the treatment of acute renal colic. Eur Urol 2018;73:583-595.

221. Wang S, Zhang L, Ma Y, et al. Nociceptive behavior following hindpaw burn injury in young rats: response to systemic morphine. Pain Med 2011;12:87-98.

222. Martyn JAJ, Mao J, Bittner EA. Opioid tolerance in critical illness. N Engl J Med 2019;380:365378.

223. Emery MA, Bates MLS, Wellman PJ, Eitan S. Burn injury decreases the antinociceptive effects of opioids. Behav Pharmacol 2017;28:285-293.

224. Holtman JR, Jr., Jellish WS. Opioid-induced hyperalgesia and burn pain. J Burn Care Res 2012; 33:692-701.

225. Kariya N, Shindoh M, Nishi S, Yukioka H, Asada A. Oral clonidine for sedation and analgesia in a burn patient. J Clin Anesth 1998;10:514-517.

226. Williams PI, Sarginson RE, Ratcliffe JM. Use of methadone in the morphine-tolerant burned paediatric patient. Br J Anaesth 1998;80:92-95.

227. Choiniere M, Grenier R, Paquette C. Patientcontrolled analgesia: a double-blind study in burn patients. Anaesthesia 1992;47:467-472.

228. Prakash S, Fatima T, Pawar M. Patient-controlled analgesia with fentanyl for burn dressing changes. Anesth Analg 2004;99:552-555, table of contents.

229. Lin YC, Huang CC, Su NY, et al. Patientcontrolled analgesia for background pain of major burn injury. J Formos Med Assoc 2019; 118:299-304.

230. Gaskell AL, Jephcott CG, Smithells JR, Sleigh JW. Self-administered methoxyflurane for pro- cedural analgesia: experience in a tertiary Australasian centre. Anaesthesia 2016;71:417-423.

231. Wasiak J, Mahar PD, McGuinness SK, et al. Intravenous lidocaine for the treatment of background or procedural burn pain. Cochrane Database Syst Rev 2014;10:CD005622.

232. Richardson $P$, Mustard $L$. The management of pain in the burns unit. Burns 2009;35:921-936.

233. Marret E, Kurdi O, Zufferey P, Bonnet F. Effects of nonsteroidal antiinflammatory drugs on patient-controlled analgesia morphine side effects: meta-analysis of randomized controlled trials. Anesthesiology 2005;102:1249-1260.

234. Ajmone-Cat MA, Bernardo A, Greco A, Minghetti L. Non-steroidal anti-inflammatory drugs and brain inflammation: effects on microglial functions. Pharmaceuticals (Basel) 2010;3:1949-1965.

235. Harirforoosh S, Asghar W, Jamali F. Adverse effects of nonsteroidal antiinflammatory drugs: an update of gastrointestinal, cardiovascular and renal complications. J Pharm Pharm Sci 2013;16: 821-847.

236. Griggs C, Goverman J, Bittner EA, Levi B. Sedation and pain management in burn patients. Clin Plast Surg 2017:44:535-540.

237. Zaal IJ, Devlin JW, Hazelbag $M$, et al. Benzodiazepine-associated delirium in critically ill adults. Intensive Care Med 2015;41:2130-2137.

238. Peng K, Zhang J, Meng XW, Liu HY, Ji FH. Optimization of postoperative intravenous patientcontrolled analgesia with opioid-dexmedetomidine combinations: an updated meta-analysis with trial sequential analysis of randomized controlled trials. Pain Physician 2017;20:569-596.

239. Jafarizadeh $H$, Lotfi $M$, Ajoudani $F$, Kiani $A$, Alinejad V. Hypnosis for reduction of background pain and pain anxiety in men with burns: a blinded, randomised, placebo-controlled study. Burns 2018;44:108-117.

240. Hoffman HG, Chambers GT, Meyer WJ, 3rd, et al. Virtual reality as an adjunctive nonpharmacologic analgesic for acute burn pain during medical procedures. Ann Behav Med 2011:41:183-191.

241. Perez-Ruvalcaba I, Sanchez-Hernandez V, Mercado-Sesma AR. Effect of a combined continuous and intermittent transcutaneous electrical nerve stimulation on pain perception of burn patients evaluated by visual analog scale: a pilot study. Local Reg Anesth 2015;8:119-122.

242. Broussard KC, Powers JG. Wound dressings: selecting the most appropriate type. Am J Clin Dermatol 2013;14:449-459.

243. Nherera L, Trueman P, Roberts C, Berg L. Silver delivery approaches in the management of partial thickness burns: a systematic review and indirect treatment comparison. Wound Repair Regen 2017;25:707-721.

244. Duran N, Duran $M$, de Jesus $M B$, Seabra $A B$, Favaro WJ, Nakazato G. Silver nanoparticles: a new view on mechanistic aspects on antimicrobial activity. Nanomedicine 2016;12:789-799.
245. Wasiak J, Cleland H, Campbell F, Spinks A. Dressings for superficial and partial thickness burns. Cochrane Database Syst Rev 2013;3: CD002106

246. Aziz Z, Abu SF, Chong NJ. A systematic review of silver-containing dressings and topical silver agents (used with dressings) for burn wounds. Burns 2012;38:307-318.

247. Aurora A, Beasy A, Rizzo JA, Chung KK. The use of a silver-nylon dressing during evacuation of military burn casualties. J Burn Care Res 2018; 39:593-597.

248. Heyneman A, Hoeksema H, Vandekerckhove D, Pirayesh A, Monstrey S. The role of silver sulphadiazine in the conservative treatment of partial thickness burn wounds: a systematic review. Burns 2016;42:1377-1386.

249. Dumville JC, Munson C, Christie J. Negative pressure wound therapy for partial-thickness burns. Cochrane Database Syst Rev 2014;12:CD006215.

250. Glass GE, Nanchahal J. The methodology of negative pressure wound therapy: separating fact from fiction. J Plast Reconstr Aesthet Surg 2012;65:989-1001.

251. Ubbink DT, Westerbos SJ, Nelson EA, Vermeulen $\mathrm{H}$. A systematic review of topical negative pressure therapy for acute and chronic wounds. Br J Surg 2008;95:685-692.

252. Kantak NA, Mistry R, Varon DE, Halvorson EG. Negative pressure wound therapy for burns. Clin Plast Surg 2017;44:671-677.

253. Jull AB, Cullum N, Dumville JC, Westby MJ, Deshpande S, Walker N. Honey as a topical treatment for wounds. Cochrane Database Syst Rev 2015;3:CD005083.

254. Vandamme L, Heyneman A, Hoeksema H, Verbelen $\mathrm{J}$, Monstrey $\mathrm{S}$. Honey in modern wound care: a systematic review. Burns 2013;39:15141525.

255. Dat AD, Poon F, Pham KB, Doust J. Aloe vera for treating acute and chronic wounds. Cochrane Database Syst Rev 2012;2:CD008762.

256. Maenthaisong R, Chaiyakunapruk N, Niruntraporn S, Kongkaew $\mathrm{C}$. The efficacy of aloe vera used for burn wound healing: a systematic review. Burns 2007;33:713-718.

257. Martinez-Zapata MJ, Marti-Carvajal AJ, Sola I, et al. Autologous platelet-rich plasma for treating chronic wounds. Cochrane Database Syst Rev 2012;10:CD006899.

258. Villela DL, Santos VLCG. Evidence on the use of platelet-rich plasma for diabetic ulcer: a systematic review. Growth Factors 2010;28:111-116.

259. Cheppudira B, Fowler M, McGhee L, et al. Curcumin: a novel therapeutic for burn pain and wound healing. Expert Opin Investig Drugs 2013; 22:1295-1303.

260. Plichta JK, Radek KA. Sugar-coating wound repair: a review of FGF-10 and dermatan sulfate in wound healing and their potential application in burn wounds. J Burn Care Res 2012;33:299-310. 
261. Dai T, Vrahas MS, Murray CK, Hamblin MR. Ultraviolet $C$ irradiation: an alternative antimicrobial approach to localized infections? Expert Rev Anti Infect Ther 2012;10:185-195.

262. Dai T, Tanaka M, Huang YY, Hamblin MR. Chitosan preparations for wounds and burns: antimicrobial and wound-healing effects. Expert Rev Anti Infect Ther 2011;9:857-879.

263. Wibbenmeyer $L$, Danks $R$, Faucher $L$, et al. Prospective analysis of nosocomial infection rates, antibiotic use, and patterns of resistance in a burn population. J Burn Care Res 2006;27:152160.

264. Bang RL, Sharma PN, Sanyal SC, Najjadah IA. Septicaemia after burn injury: a comparative study. Burns 2002;28:746-751.

265. Hogan BK, Wolf SE, Hospenthal DR, et al. Correlation of American Burn Association sepsis criteria with the presence of bacteremia in burned patients admitted to the intensive care unit. J Burn Care Res 2012;33:371-378.

266. Mokline A, Garsallah L, Rahmani I, et al. Procalcitonin: a diagnostic and prognostic biomarker of sepsis in burned patients. Ann Burns Fire Disasters 2015;28:116-120.

267. Paratz JD, Lipman J, Boots RJ, Muller MJ, Paterson DL. A new marker of sepsis post burn injury? Crit Care Med 2014;42:2029-2036.

268. Cabral L, Afreixo V, Almeida L, Paiva JA. The use of procalcitonin (PCT) for diagnosis of sepsis in burn patients: a meta-analysis. PLoS One 2016; 11:e0168475.

269. Cabral L, Afreixo V, Meireles R, et al. Checking procalcitonin suitability for prognosis and antimicrobial therapy monitoring in burn patients. Burns Trauma 2018;6:10.

270. Hultman CS, van Duin D, Sickbert-Bennett E, et al. Systems-based practice in burn care: prevention, management, and economic impact of health care-associated infections. Clin Plast Surg 2017:44:935-942.

271. Barajas-Nava LA, Lopez-Alcalde J, Roque i Figuls M, Sola I, Bonfill Cosp X. Antibiotic prophylaxis for preventing burn wound infection. Cochrane Database Syst Rev 2013;6: CD008738.

272. Bratzler DW, Hunt DR. The surgical infection prevention and surgical care improvement projects: national initiatives to improve outcomes for patients having surgery. Clin Infect Dis 2006; 43:322-330.

273. Naik Bl, Roger C, Ikeda K, et al. Comparative total and unbound pharmacokinetics of cefazolin administered by bolus versus continuous infusion in patients undergoing major surgery: a randomized controlled trial. Br J Anaesth 2017;118: 876-882.

274. Ramos G, Cornistein W, Cerino GT, Nacif G. Systemic antimicrobial prophylaxis in burn patients: systematic review. J Hosp Infect 2017;97: 105-114.
275. Bennett MH, French C, Schnabel A, Wasiak J, Kranke $P$, Weibel S. Normobaric and hyperbaric oxygen therapy for the treatment and prevention of migraine and cluster headache. Cochrane Database Syst Rev 2015. [Epub ahead of print]; DOI: 10.1002/14651858.CD005219.pub3.

276. Eskes A, Vermeulen H, Lucas C, Ubbink DT. Hyperbaric oxygen therapy for treating acute surgical and traumatic wounds. Cochrane Database Syst Rev 2013;12:CD008059.

277. Chiang IH, Chen SG, Huang KL, Chou YC, Dai NT, Peng CK. Adjunctive hyperbaric oxygen therapy in severe burns: experience in Taiwan Formosa Water Park dust explosion disaster. Burns 2017; 43:852-857.

278. Kurmis $\mathrm{R}$, Heath $\mathrm{K}$, Ooi $\mathrm{S}$, et al. A prospective multi-center audit of nutrition support parameters following burn injury. J Burn Care Res 2015; 36:471-477.

279. Abdullahi A, Jeschke MG. Nutrition and anabolic pharmacotherapies in the care of burn patients Nutr Clin Pract 2014;29:621-630

280. Real DS, Reis RP, Piccolo MS, Okamoto RH Gragnani A, Ferreira LM. Oxandrolone use in adult burn patients. Systematic review and meta-analysis. Acta Cir Bras 2014;29(Suppl 3): 68-76.

281. Breederveld RS, Tuinebreijer WE. Recombinant human growth hormone for treating burns and donor sites. Cochrane Database Syst Rev 2012; 12:CD008990

282. Jeschke MG, Kulp GA, Kraft R, et al. Intensive insulin therapy in severely burned pediatric patients: a prospective randomized trial. Am J Respir Crit Care Med 2010;182:351-359.

283. Stoecklin P, Delodder F, Pantet O, Berger MM. Moderate glycemic control safe in critically ill adult burn patients: a 15 year cohort study. Burns 2016;42:63-70.

284. Flores 0, Stockton K, Roberts JA, Muller MJ, Paratz JD. The efficacy and safety of adrenergic blockade after burn injury: a systematic review and meta-analysis. J Trauma Acute Care Surg 2016;80:146-155.

285. Czaja AJ, McAlhany JC, Pruitt BA, Jr. Acute duodenitis and duodenal ulceration after burns. Clinical and pathological characteristics. JAMA 1975;232:621-624.

286. Siddiqui AH, Siddiqui F. Curling Ulcer (StressInduced Gastric). Treasure Island (FL): StatPearls Publishing, LLC, 2018.

287. Dellinger RP, Levy MM, Carlet JM, et al. Surviving Sepsis Campaign: international guidelines for management of severe sepsis and septic shock: 2008. Intensive Care Med 2008;34:17-60.

288. Alhazzani W, Alenezi F, Jaeschke RZ, Moayyedi P, Cook DJ. Proton pump inhibitors versus histamine 2 receptor antagonists for stress ulcer prophylaxis in critically ill patients: a systematic review and meta-analysis. Crit Care Med 2013; 41:693-705
289. Dowton SB, Colten HR. Acute phase reactants in inflammation and infection. Semin Hematol 1988:25:84-90.

290. Deftos LJ, Roos BA, Parthemore JG. Calcium and skeletal metabolism. West J Med 1975;123: 447-458.

291. Griffin JH, Mosnier LO, Zlokovic BV. Protein C anticoagulant and cytoprotective pathways. Int $\mathrm{J}$ Hematol 2012:95:333-345.

292. Whitmont K. Activated Protein C in Cutaneous Wound Healing. Sydney: University of Sydney, 2010.

293. Griffin JH, Fernández JA, Gale AJ, Mosnier LO. Activated protein C. J Thromb Haemost 2007;5: 73-80.

294. Koya RC, Fujita H, Shimizu S, et al. Gelsolin inhibits apoptosis by blocking mitochondrial membrane potential loss and cytochrome $\mathrm{c}$ release. J Biol Chem 2000;275:15343-15349.

295. Varon C, Tatin F, Moreau V, et al. Transforming growth factor beta induces rosettes of podosomes in primary aortic endothelial cells. Mol Cell Biol 2006:26:3582-3594.

296. Devarajan P, Mookhtiar K, Van Wart H, Berliner $\mathrm{N}$. Structure and expression of the cDNA encoding human neutrophil collagenase. Blood 1991;77:2731-2738

297. Delclaux C, Delacourt C, D'Ortho MP, Boyer V Lafuma C, Harf A. Role of gelatinase B and elastase in human polymorphonuclear neutrophil migration across basement membrane. Am J Respir Cell Mol Biol 1996;14:288-295.

298. Opdenakker G, Van den Steen PE, Dubois B, et al. Gelatinase $B$ functions as regulator and effector in leukocyte biology. J Leukoc Biol 2001; 69:851-859

299. Dubois B, Starckx S, Pagenstecher A, Oord J Arnold B, Opdenakker G. Gelatinase B deficiency protects against endotoxin shock. Eur J Immunol 2002;32:2163-2171.

300. Vu TH, Shipley JM, Bergers G, et al. MMP-9/ gelatinase $B$ is a key regulator of growth plate angiogenesis and apoptosis of hypertrophic chondrocytes. Cell 1998;93:411-422.

301. Buisson AC, Zahm JM, Polette M, et al. Gelatinase $B$ is involved in the in vitro wound repair of human respiratory epithelium. J Cell Physiol 1996;166:413-426.

302. Brew K, Nagase H. The tissue inhibitors of metalloproteinases (TIMPs): an ancient family with structural and functional diversity. Biochim Biophys Acta 2010;1803:55-71.

303. Brew K, Dinakarpandian D, Nagase H. Tissue inhibitors of metalloproteinases: evolution, structure and function. Biochim Biophys Acta 2000;1477: 267-283.

304. Olson ST, Bjork I. Regulation of thrombin activity by antithrombin and heparin. Semin Thromb Hemost 1994;20:373-409. 
305. Zhu J, Paul WE. CD4 T cells: fates, functions, and faults. Blood 2008;112:1557-1569.

306. Toscano MA, Bianco GA, Ilarregui JM, et al. Differential glycosylation of $\mathrm{TH} 1, \mathrm{TH} 2$ and $\mathrm{TH}-17$ effector cells selectively regulates susceptibility to cell death. Nat Immunol 2007;8:825-834.

307. Zambrano-Zaragoza JF, Romo-Martinez EJ, DuranAvelar Mde J, Garcia-Magallanes N, VibancoPerez N. Th17 cells in autoimmune and infectious diseases. Int J Inflam 2014;2014:651503.

308. Weaver CT, Elson CO, Fouser LA, Kolls JK. The Th17 pathway and inflammatory diseases of the intestines, lungs, and skin. Annu Rev Pathol 2013;8:477-512.

309. Holtmeier W, Kabelitz D. gammadelta T cells link innate and adaptive immune responses. Chem Immunol Allergy 2005;86:151-183.

310. Moser B, Eberl M. $\gamma \delta$ T-APCs: a novel tool for immunotherapy? Cell Mol Life Sci 2011;68:24432452.

311. Kolaczkowska E, Kubes P. Neutrophil recruitment and function in health and inflammation. Nat Rev Immunol 2013;13:159-175.

312. McFarlin BK, Venable AS, Henning AL, Williams RR, Prado EA. Assessment of granulocyte subset activation: new information from image-based flow cytometry. Methods Mol Biol 2016;1389: 177-185.

313. Chen G, Goeddel DV. TNF-R1 signaling: a beautiful pathway. Science 2002;296:1634-1635.

314. Gaur U, Aggarwal BB. Regulation of proliferation, survival and apoptosis by members of the TNF superfamily. Biochem Pharmacol 2003;66: 1403-1408.

315. Pedersen BK, Febbraio MA. Muscle as an endocrine organ: focus on muscle-derived interleukin6. Physiol Rev 2008:88:1379-1406.

316. Heinrich PC, Behrmann I, Haan S, Hermanns HM, Muller-Newen G, Schaper F. Principles of interleukin (IL)-6-type cytokine signalling and its regulation. Biochem J 2003;374:1-20.

317. Anestakis D, Petanidis S, Kalyvas S, et al. Mechanisms and applications of interleukins in cancer immunotherapy. Int J Mol Sci 2015;16: 1691-1710.

318. Francisco-Cruz A, Aguilar-Santelises M, RamosEspinosa 0, et al. Granulocyte-macrophage colonystimulating factor: not just another haematopoietic growth factor. Med Oncol 2014;31:774.
319. Sokol CL, Barton GM, Farr AG, Medzhitov R. A mechanism for the initiation of allergen-induced T helper type 2 responses. Nat Immunol 2008;9: 310-318.

320. Arenas-Ramirez N, Woytschak J, Boyman 0. Interleukin-2: biology, design and application. Trends Immunol 2015;36:763-777.

321. Milburn MV, Hassell AM, Lambert MH, et al. A novel dimer configuration revealed by the crystal structure at $2.4 \mathrm{~A}$ resolution of human interleukin-5. Nature 1993;363:172-176.

322. Sanderson CJ. Interleukin-5, eosinophils, and disease. Blood 1992;79:3101-3109.

323. Muegge K, Vila $M$, Durum S. Interleukin-7: a cofactor for $V(D) J$ rearrangement of the $T$ cell receptor beta gene. Science 1993;261:93-95.

324. Hsieh CS, Macatonia SE, Tripp CS, Wolf SF, O'Garra A, Murphy KM. Development of TH1 $\mathrm{CD4}^{+} \mathrm{T}$ cells through IL-12 produced by Listeria-induced macrophages. Science 1993; 260:547-549.

325. Minty A, Chalon P, Derocq JM, et al. Interleukin13 is a new human lymphokine regulating inflammatory and immune responses. Nature 1993: 362:248-250.

326. Starnes T, Broxmeyer HE, Robertson MJ, Hromas R. Cutting edge: IL-17D, a novel member of the IL-17 family, stimulates cytokine production and inhibits hemopoiesis. J Immunol 2002;169: 642-646.

327. Schoenborn JR, Wilson CB. Regulation of interferon-gamma during innate and adaptive immune responses. Adv Immunol 2007;96:41101.

328. Arend WP, Malyak M, Guthridge CJ, Gabay C. Interleukin-1 receptor antagonist: role in biology. Annu Rev Immunol 1998;16:27-55.

329. Köhidai L, Csaba G. Chemotaxis and chemotactic selection induced with cytokines (IL-8, RANTEs and TNF- $\alpha$ ) in the unicellular tetrahymena pyriformis. Cytokine 1998;10:481-486.

330. Carr MW, Roth SJ, Luther E, Rose SS, Springer TA. Monocyte chemoattractant protein 1 acts as a T-lymphocyte chemoattractant. Proc Natl Acad Sci U S A 1994;91:3652-3656.

331. Miller MD, Hata S, De Waal Malefyt R, Krangel MS. A novel polypeptide secreted by activated human T lymphocytes. J Immunol 1989;143: 2907-2916.

\section{ABBREVIATIONS AND ACRONYMS}

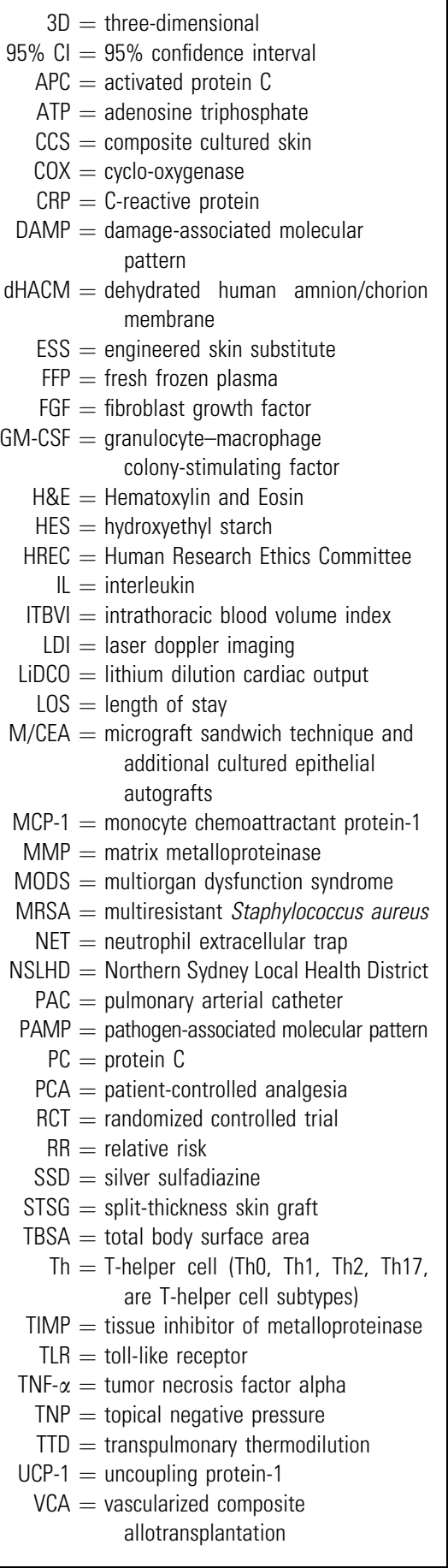

